Article

\title{
Designing Intelligent MIMO Nonlinear Controller Based on Fuzzy Cognitive Map Method for Energy Reduction of the Buildings
}

\author{
Farinaz Behrooz ${ }^{1, *(\mathbb{D})}$, Rubiyah Yusof ${ }^{1,2}$, Norman Mariun ${ }^{3,4}$, Uswah Khairuddin ${ }^{1,2}$ and \\ Zool Hilmi Ismail ${ }^{1,2}$ (D) \\ 1 Malaysia -Japan International Institute of Technology (MJIIT), Universiti Teknologi Malaysia, \\ Kuala Lumpur 54100, Malaysia \\ 2 Centre for Artificial Intelligence and Robotics (CAIRO), Universiti Teknologi Malaysia, Kuala \\ Lumpur 54100, Malaysia \\ 3 Department of Electrical and Electronic Engineering, Faculty of Engineering, University Putra Malaysia, \\ Serdang 43400, Selangor, Malaysia \\ 4 Centre for Advanced Power and Energy Research, Faculty of Engineering, University Putra Malaysia, \\ Serdang 43400, Selangor, Malaysia \\ * Correspondence: fery_behrooz@yahoo.com; Tel.: +60-10-4315144
}

Received: 27 May 2019; Accepted: 9 July 2019; Published: 16 July 2019

\begin{abstract}
Designing a suitable controller for air-conditioning systems to reduce energy consumption and simultaneously meet the requirements of the system is very challenging. Important factors such as stability and performance of the designed controllers should be investigated to ensure the effectiveness of these controllers. In this article, the stability and performance of the fuzzy cognitive map (FCM) controller are investigated. The FCM method is used to control the direct expansion air conditioning system (DX A/C). The FCM controller has the ability to do online learning, and can achieve fast convergence thanks to its simple mathematical computation. The stability analysis of the controller was conducted using both fuzzy bidirectional associative memories (FBAMs) and the Lyapunov function. The performances of the controller were tested based on its ability for reference tracking and disturbance rejection. On the basis of the stability analysis using FBAMS and Lyapunov functions, the system is globally stable. The controller is able to track the set point faithfully, maintaining the temperature and humidity at the desired value. In order to simulate the disturbances, heat and moisture load changed to measure the ability of the controller to reject the disturbance. The results showed that the proposed controller can track the set point and has a good ability for disturbance rejection, making it an effective controller to be employed in the DX A/C system and suitable for a nonlinear robust control system.
\end{abstract}

Keywords: intelligent control (IC); fuzzy cognitive map (FCM); direct expansion air-conditioning (DX A/C); nonlinear; coupling effect; MIMO; stability analysis; Lyapunov function; fuzzy bidirectional associative memories (FBAMs)

\section{Introduction}

Heating, ventilating, and air-conditioning (HVAC) systems are a major cause of energy consumption in the building automation systems (BAS). Because of the depletion of energy sources in the world and the worsening fuel crisis, the need for advanced, improved control systems designs aimed at less energy usage and better performance are becoming a significant challenge for control engineers [1]. Because of the critical influence of HVAC systems on energy and power consumption, it is imperative to be familiar with the operation as well as the structure of HVAC systems [2]. 
Nowadays, the use of different controllers on HVAC systems is considered as an important issue, with the aim of increasing the system performance, by reason of their high installation demand in buildings and their huge energy consumption.

The direct expansion air-conditioning (DX A/C) system is considered as a subgroup of HVAC systems. The mentioned system has two types of units, window units and split units, which are frequently employed in small- to medium-sized buildings by reason of having a simple configuration, low cost maintenance, and higher energy efficiency $[3,4]$.

According to the authors of [2], energy efficacy and indoor thermal conditions are the main objectives one needs to take into account when designing HVAC or $\mathrm{A} / \mathrm{C}$ systems. Because of the complicated features of HVAC and A/C systems, attaining the mathematical model of HVAC and air conditioning systems is intricate and difficult. Likewise, designing an appropriate controller becomes a big challenge [5,6]. HVAC system is a multiple-Input and multiple-output (MIMO) system, sometimes with coupled parameters [7]. Moreover, it is a complex nonlinear system, which makes deriving the exact mathematical model a challenging task [3]. Consequently, the control system must be able to deal simultaneously with cross-coupling effects, nonlinearity, and uncertainty of the system. The high energy consumption of these systems calls for an intelligent control system that can adjust the parameters according to the systems' demands, so that it could prevent energy loss and balance between the energy consumption and thermal comfort. Needless to say, an appropriate controller could prevent a significant amount of energy loss [8]. However, designing a suitable controller for the air conditioning system as a nonlinear, complex MIMO system with coupled parameters is still a challenging task [8]. According to the authors of [9], a small increase in system operating proficiency causes major energy savings. Therefore, various studies have investigated different control methods and optimizations in the HVAC areas.

In the case of the DX A/C system, although one can utilize single-input and single-output (SISO) control approaches to control each parameter separately, by decoupling the effects of control variables, yet it degrades the performance of the system [10]. For solving the aforementioned problems and improving the system performance, the control of the DX A/C system can be viewed as a MIMO control system [4]. However, based on the literature, MIMO control systems have mostly been employed on the linearized model of the systems. Thus, the control system is locally stable. In other words, the controller has the ability to stabilize the system around a certain operating point, and stability of the system is not guaranteed outside of a small vicinity of the operating point [11]. Therefore, nonlinear control techniques have been introduced into the DX A/C systems [12,13]. Owing to the complexity and uncertainty of the system, the application of nonlinear control techniques to the system is limited. Complicated mathematical analysis, stability analysis, and the need for the entire states are some aspects that hinder the use of nonlinear control methods [13]. Feedback linearization, Lyapunov stability theory, and adaptive control are some of the approaches that have been applied to the system [14].

Some other control methods like model predictive control (MPC) are successfully applied in this field, but it is necessary to identify a suitable model for the system [15] and installation could be expensive. This means that an accurate dynamic model from the system is required and, considering the uncertainties, makes the problem very difficult to solve.

On the other hand, conventional controllers like a proportional-integral-derivative (PID) controller, usually implemented in a feedback control scheme, are the most applied controllers in this area because of the simplicity of the control law and easy implementation in continuous-time [16-18]. The feedback control scheme depends heavily on feedback sensors, which have some disadvantages such as cost, reliability, and noise, which can affect the output of the system. Moreover, control systems using PID controllers usually have overshoot or undershoot, which means they put sudden pressure on the actuators and reduce the actuators performance over time. This method suffers from disadvantages such as long testing times and limited performance. Tuning the parameters of the controller is cumbersome, and choosing the improper gains of PID controllers can cause the system to 
be unstable [19]. Considering the above mentioned challenges, a simple control method that can deal with the complexity of the system and be practically feasible is of interest.

\section{Construction of the DX A/C System}

The DX A/C system is constructed from two parts, including an air-distribution subsystem and DX refrigeration plant [3]. The refrigeration plant contains a condenser, oil separator, DX evaporator, electronic expansion valve (EEV), receiver, and variable speed compressor. The structure of air-distribution sub-system is composed of an air conditioned room, ductwork, and centrifugal supply fan (variable-speed) [3]. This system is characteristically complex, time varying, and nonlinear, with very effective coupled parameters of supplied air humidity and temperature in the evaporator. Controlling this system was done by varying the speed of the motor compressor and speed of supply fan, in order to attain the preferred humidity and temperature. Figure 1 shows the diagram of the DX $\mathrm{A} / \mathrm{C}$ framework.

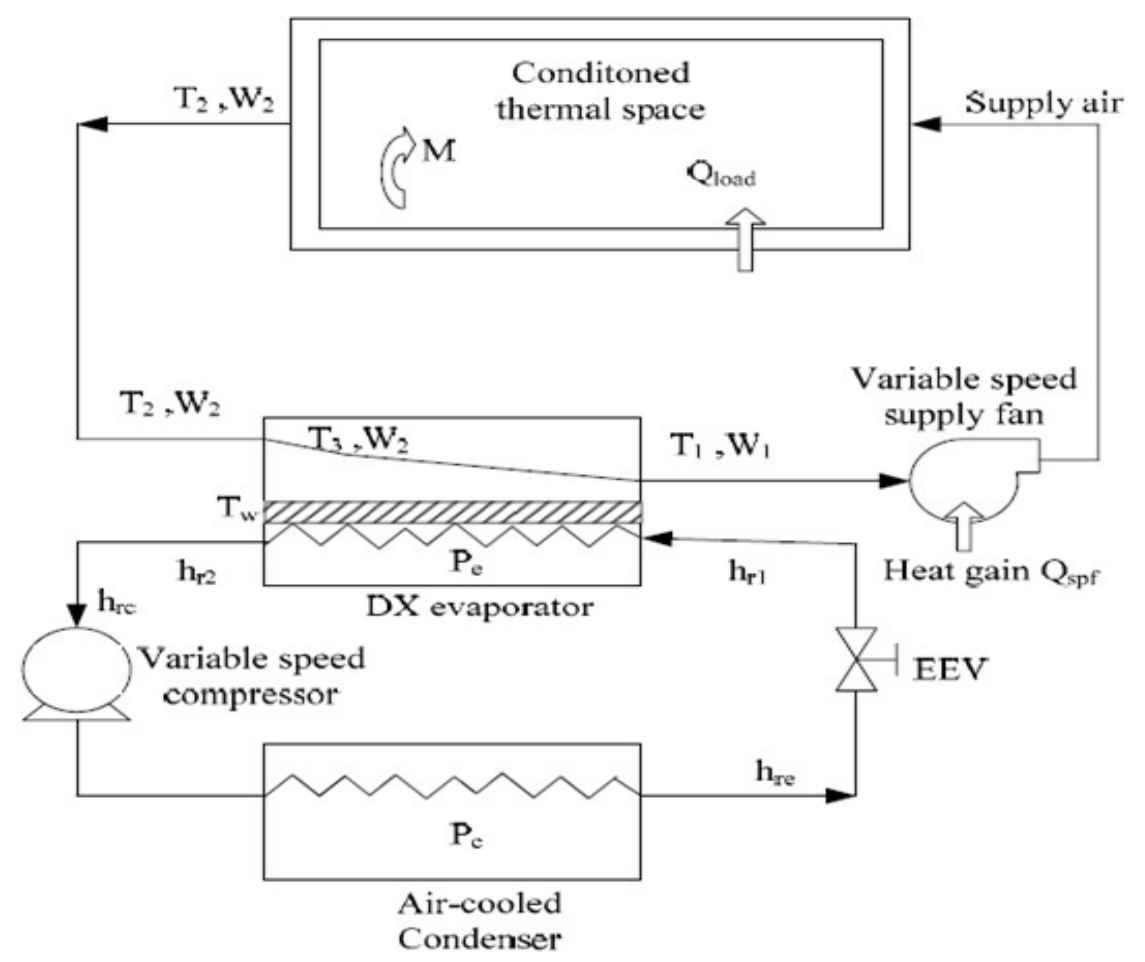

Figure 1. Direct expansion air-conditioning (DX A/C) framework. EEV, electronic expansion valve.

The system mathematical model is extracted from the mass and energy balance conservation principals and the dynamic system equations [3]. The working fluid of the refrigeration plant is Refrigerant 22 (R22), which operates on the basis of the vapor compression cycle's principle [20,21]. On the basis of the work of [3], the evaporator acts as an air cooling coil to simultaneously dehumidify and cool down the passing air through the evaporator. The emerging moisture and temperature content to the air side of the DX evaporator are $W_{2}$ and $T_{2}$, respectively, by the no fresh air assumption [22]. The passing air temperature through the evaporator has declined to the $T_{3}$ value along the dry-cooling section [3]. Because of the small area of the dry-cooling section, the entire evaporator wall temperature could be assumed to have the same temperature $\left(T_{w}\right)$. Equation (1) is obtained using the energy balance principle for the dry-cooling section [3].

$$
C_{p} \rho V_{h 1}\left(\frac{d T_{3}}{d t}\right)=C_{p} \rho f\left(T_{2}-T_{3}\right)+\alpha_{1} A_{1}\left(T_{w}-\left(\frac{\left(T_{2}+T_{3}\right)}{2}\right)\right.
$$


The temperature of evaporator tube wall is shown by $T_{w}$. The airflow rate is $f$. The volume of the dry-cooling section is illustrated by $V_{h 1}$, and the area of the heat transfer for dry-cooling region is demonstrated by $A_{1}$. Oppositely, the heat transfer and the sensible heat transfer obtained in the wet-cooling section between the evaporator wall and air. It is worth mentioning that the coupling effect of air cooling and air dehumidification mostly occurs in the wet-cooling section. The supplied air temperature by evaporator is shown by $T_{1}$, the wet-cooling section volume is $V_{h 2}$, the wet-cooling section area in air side is $A_{2}$, and the vaporization of water's latent heat is shown by $h_{f g h}$. Thus, the wet-cooling section energy balance is attained as follows:

$$
C_{p} \rho V_{h 2}\left(\frac{d T_{1}}{d t}\right)+\rho V_{h 2} h_{f g h}\left(\frac{d W_{1}}{d t}\right)=C_{p} \rho f\left(T_{3}-T_{1}\right)+\rho f h_{f g h}\left(W_{2}-W_{1}\right)+\alpha_{2} A_{2}\left(T_{w}-\frac{\left(T_{3}+T_{1}\right)}{2}\right) .
$$

The DX evaporator outlet supply air is assumed to be $95 \%$ saturated. As a result, the coupled supplied air humidity and air temperature by evaporator could be extracted using curve fitting and plotting [3,4] as follows:

$$
\left(\frac{d W_{1}}{d t}\right)-\left(2 \times 0.0198 T_{1}+0.085\right)\left(\frac{d T_{1}}{d t}\right)=0 .
$$

As the division of the refrigerant side and air side is the evaporator wall, and because of the considerable different thermal inertia of the air and refrigerant, dynamics responding to changes on the refrigerant side are considerably faster than on the air side. In other words, it is quite time consuming for a full response on the air side compared with the refrigerant side. Consequently, using the same mass flow rate assumption for both inlet refrigerant to evaporator and outlet refrigerant from evaporator, the energy balance equation of the evaporator wall can be considered as follows:

$$
\left(C_{p} \rho V\right)_{w}\left(\frac{d T_{w}}{d t}\right)=\alpha_{1} A_{1}\left(\left(\frac{T_{2}+T_{3}}{2}\right)-T_{w}\right)+\alpha_{2} A_{2}\left(\left(\frac{\left(T_{3}+T_{1}\right)}{2}\right)-T_{w}\right)-\frac{\left(s V_{c o m}\right)}{v_{\mathcal{S}}\left(\frac{P_{c}}{P_{e}}\right)^{\frac{1}{\beta}}}\left(h_{r 2}-h_{r 1}\right) .
$$

The calculation of the rotor compressor swept volume $\left(V_{\text {com }}\right)$ was done by applying the geometric parameters of compressor. The parameter $s$ is speed of motor compressor and superheated refrigerant specific volume is $v_{s}$. According to the energy conservation principle for the air-conditioned room, the sensible energy balance equation is as follows:

$$
C_{p} \rho V\left(\frac{d T_{2}}{d t}\right)=C_{p} \rho f\left(T_{1}-T_{2}\right)+Q_{s p l}+Q_{l o a d} .
$$

The feedback of air temperature $\left(T_{2}\right)$ and air humidity $\left(W_{2}\right)$ from the air-conditioned room are considered equal to the thermal condition of the air-conditioned room. The volume of the flow rate is demonstrated by $f$. The supply fan heat gain is shown by $Q_{s p l}$. The volume of the air-conditioned room is $V$, and sensible load of room is illustrated by $Q_{\text {load }}$. Referring to the temperature, by increasing the air flow rate, the supply fan heat gain increases as follows:

$$
Q_{s p l}=K_{s p l} f
$$

On the other hand, for humidity, the air-conditioned room's moisture mass balance is as follows:

$$
\rho V\left(\frac{d W_{2}}{d t}\right)=\rho f\left(W_{1}-W_{2}\right)+M
$$

The humidity load generation in the air-conditioned room is M. According to the authors of [3], Equations (1)-(5) and (7), which are all first order differential equations, could form the dynamic model of the DX A/C system. On the basis of the work done by Qi [22], Equations (1)-(7) are used as a dynamic mathematical model of the experimental DX A/C system and have been experimentally validated. 
Hence, these equations can be used as the DX A/C system model to design a multivariable control system. In order to design the multivariable nonlinear controller on the DX A/C system, the mentioned differential equations should be re-written in the state-space format. Therefore, the state-space form of the model can be expressed in the following compact format:

$$
\dot{X}=D^{-1} \cdot g_{1}(X, U)+D^{-1} \cdot g_{2}(Z) .
$$

The state variables are as vector $\boldsymbol{X},\left(\boldsymbol{X}=\left[T_{1} ; T_{2} ; T_{3} ; T_{w} ; W_{1} ; W_{2}\right]^{T}\right)$, control variables are as vector $\boldsymbol{U},\left(\boldsymbol{U}=[f, s]^{T}\right)$, and disturbances of the system are as vector $\boldsymbol{Z},\left(\boldsymbol{Z}=[\text { Qload; } M]^{T}\right) . g_{1}$ and $g_{2}$ are functions defined as follows:

$$
\begin{gathered}
g_{1}(X, U)=\left[\begin{array}{c}
C_{p} \rho f\left(T_{3}-T_{1}\right)+\rho f h_{f g h}\left(W_{2}-W_{1}\right)+\alpha_{2} A_{2}\left(T_{w}-\frac{T_{3}+T_{1}}{2}\right) \\
C_{p} \rho f\left(T_{1}-T_{2}\right)+K_{s p l} f \\
C_{p} \rho f\left(T_{2}-T_{3}\right)+\alpha_{1} A_{1}\left(T_{w}-\frac{T_{2}+T_{3}}{2}\right) \\
\alpha_{1} A_{1}\left(\frac{T_{2}+T_{3}}{2}-T_{w}\right)+\alpha_{2} A_{2}\left(\frac{T_{3}+T_{1}}{2}-T_{w}\right)-\frac{\left(s V_{c o m}\right)}{v_{s}\left(\frac{P_{c}}{P_{e}}\right)^{\frac{1}{\beta}}}\left(h_{r 2}-h_{r 1}\right) \\
0 \\
\rho f\left(W_{1}-W_{2}\right)
\end{array}\right], \\
0 \\
g_{2}(Z)=\left[\begin{array}{c}
0 \\
Q_{l o a d} \\
0 \\
0 \\
0 \\
M
\end{array}\right], \\
0 \\
C_{p} \rho V_{h 2} \\
0
\end{gathered}
$$

\section{Open Loop Response of the Linearized Model of the System}

With the purpose of model validation, the results of the open loop system with step input for the fan flow rate as well as for compressor speed were compared to the same results of the work of [22]. The results of [22] are based on the experimental model of the DX A/C system, in which the experimental results were compared with the simulation results of the system according to the extracted dynamic mathematical model of the system. According to the results of [22], the dynamic mathematical model of the system was validated and represented as a multivariable control-oriented modelling of a direct expansion (DX) air conditioning (A/C) system. In this work, the open loop simulation results of the DX A/C model based on the dynamic mathematical equations of the system are compared to the simulation and experimental results of the same model, which was done by the authors of [22]. First, the results of the step response for the fan flow rate were compared. At $290 \mathrm{~s}$, the fan flow rate decreased by changing the speed of the fan motor from $2448 \mathrm{rpm}$ to $2160 \mathrm{rpm}$ or from $41 \mathrm{~Hz}$ to $36 \mathrm{~Hz}$. The block diagram of the open loop system in response to a step change in fan flow rate is indicated in Figure 2. 


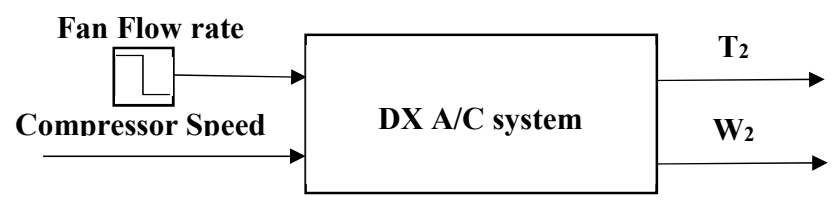

Figure 2. Block diagram of the open loop in step response of fan flow rate.

The results of Figure 3 show that the temperature of the air-conditioned room after $290 \mathrm{~s}$ started to increase to $24.15{ }^{\circ} \mathrm{C}$ and stabilized at $600 \mathrm{~s}$. By reducing the fan flow rate, the effect of the flow rate of the fan on declining the temperature of the room decreased. As is clear from Figure 3, the temperature of the air conditioned room $\left(T_{2}\right)$ by decreasing the speed of the fan and, consequently, decreasing the flow rate of the fan, started to increase from $24{ }^{\circ} \mathrm{C}$ at $290 \mathrm{~s}$ to $24.15^{\circ} \mathrm{C}$ and stabilized at $600 \mathrm{~s}$ and remained stable in this condition.

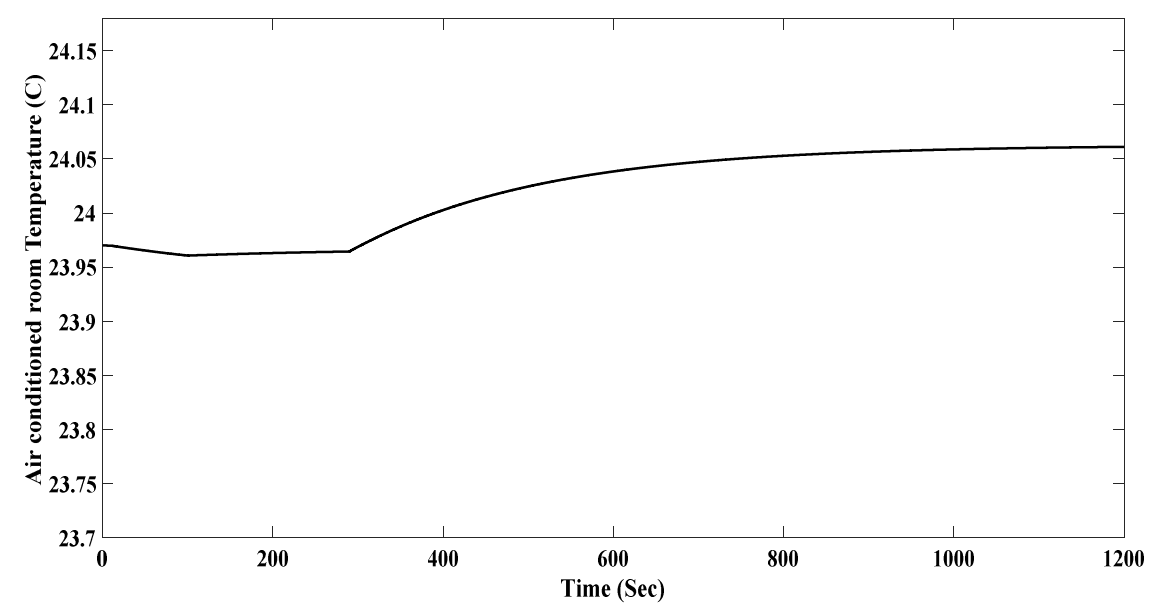

Figure 3. Open loop redo simulation result of air conditioned room temperature in step response of fan flow rate.

Also, the results of Figure 4 indicate that the humidity ratio of the air conditioned room after $290 \mathrm{~s}$ declined from $0.01130 \mathrm{~kg} / \mathrm{Kg}$ to $0.01113 \mathrm{~kg} / \mathrm{Kg}$ and remained stable after $600 \mathrm{~s}$. As the humidity of the air-conditioned room is affected less by varying the fan flow rate, by reduction of the fan flow rate, the humidity of the air-conditioned room was affected more by compressor speed, and consequently decreased.

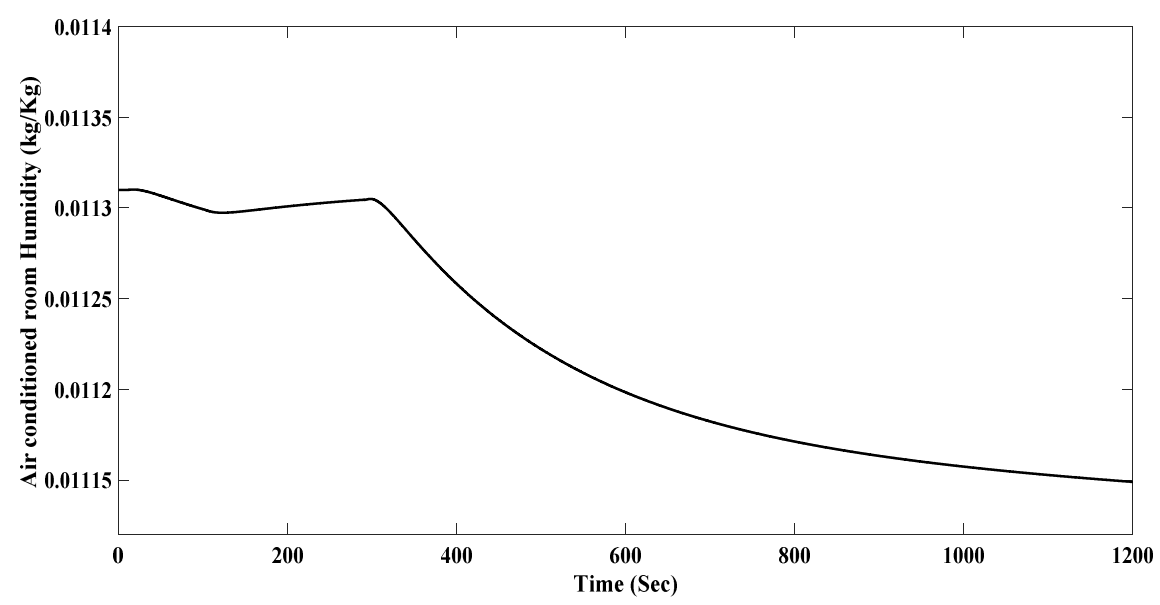

Figure 4. Open loop redo simulation result of air conditioned room humidity ratio in step response of fan flow rate. 
In the next step, the results of the step input for the compressor speed were investigated. The block diagram of the open loop system in step response of compressor speed is illustrated in Figure 5.

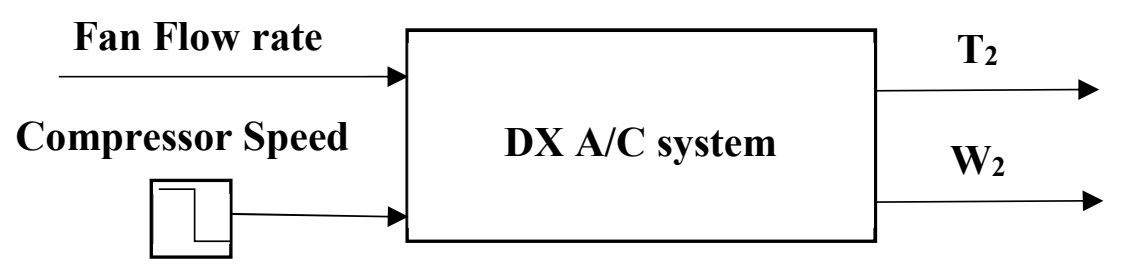

Figure 5. Schematic diagram of the open loop in step response of motor compressor speed.

At $400 \mathrm{~s}$, the speed of compressor increased from $3960 \mathrm{rpm}$ to $4488 \mathrm{rpm}$ or from $66 \mathrm{~Hz}$ to $75 \mathrm{~Hz}$. The results of Figure 6 display the temperature of the air-conditioned room. Because of the increasing speed of the compressor at $400 \mathrm{~s}$, as is obvious in Figure 6, the room temperature decreased from $24^{\circ} \mathrm{C}$ to $23.75{ }^{\circ} \mathrm{C}$ and was maintained. In addition, the results of Figure 7 illustrate that the humidity ratio of the air-conditioned room. As is obvious from Figure 7, by increasing the compressor speed at $400 \mathrm{~s}$, the humidity of the room reduced from $0.0113 \mathrm{~kg} / \mathrm{Kg}$ to $0.0111 \mathrm{~kg} / \mathrm{Kg}$ and stabilized after $500 \mathrm{~s}$.

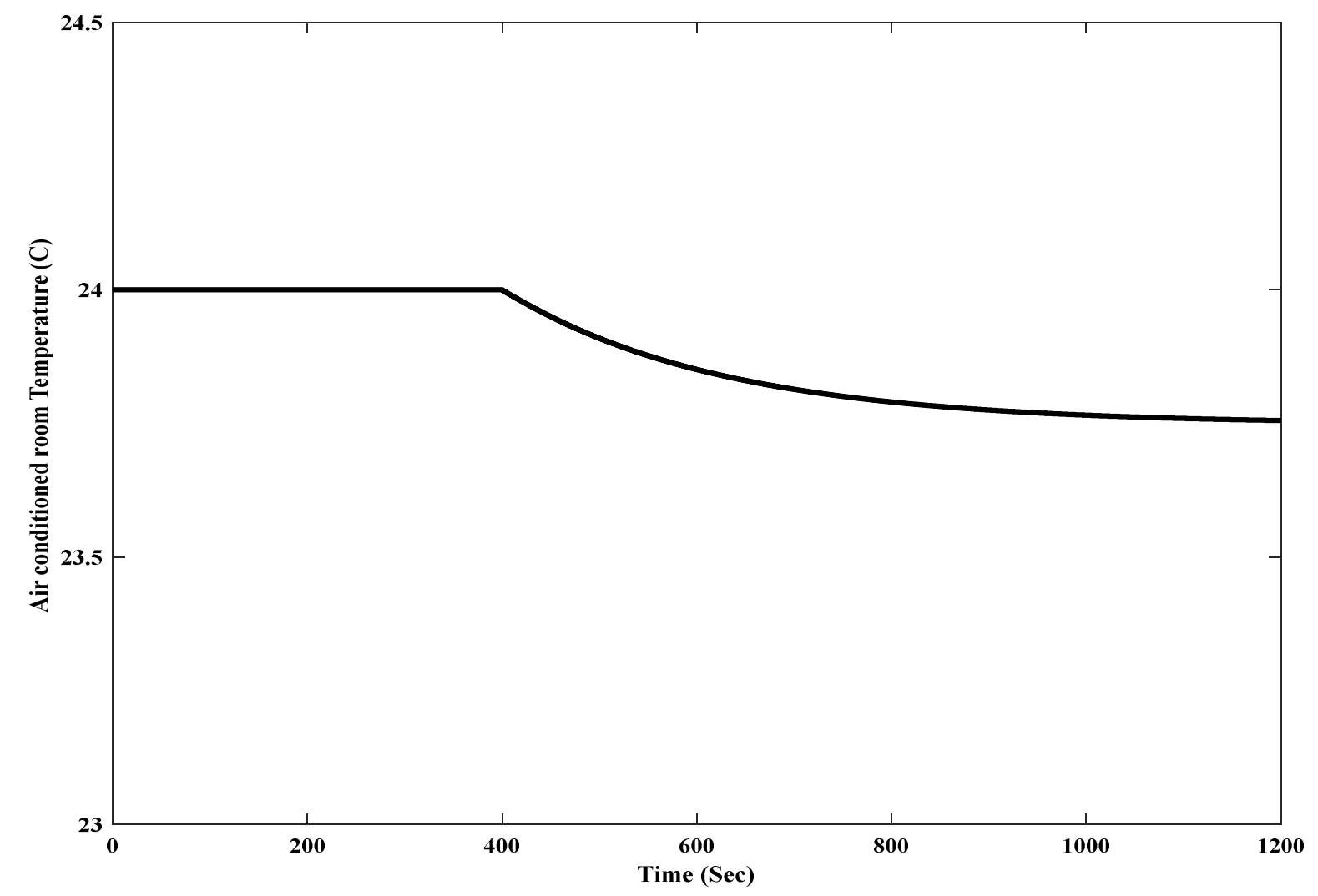

Figure 6. Open loop redo simulation result of air conditioned room temperature in step response of compressor speed.

The comparison between results by [22] and simulation results of this work shows that the dynamic mathematical model used in this research has almost similar behavior to the experimental model and validated simulation model in the work of [22]. Thus, the mathematical model used in this work represents the experimental model of the DX A/C system. 


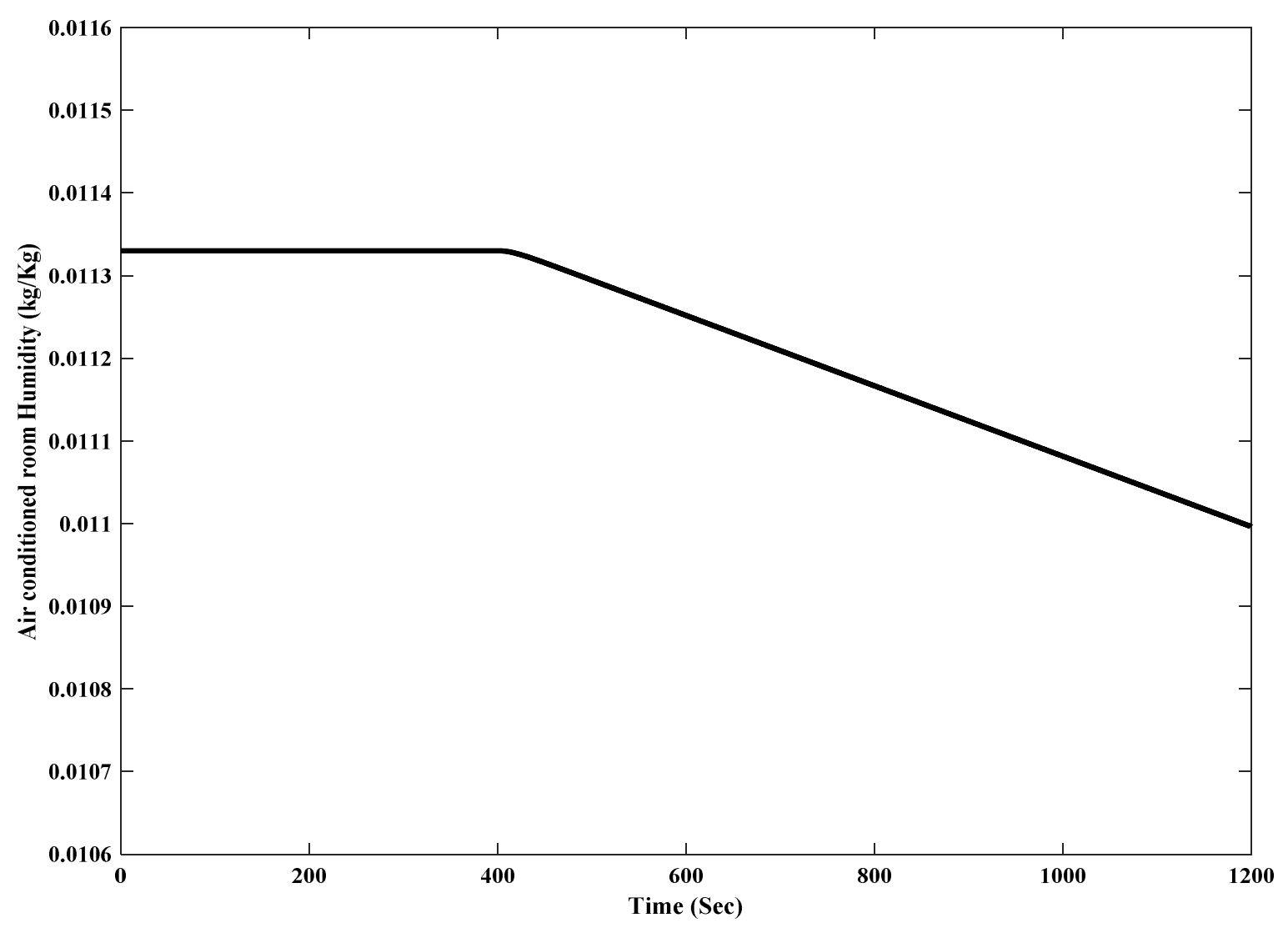

Figure 7. Open loop redo simulation result of air conditioned room humidity ratio in step response of compressor speed.

\section{Fuzzy Cognitive Map}

The development of technologies increases complex and nonlinear behaviours in the systems. Therefore, the requirement for new methods for analysing the systems is feasible [23]. The fuzzy cognitive map (FCM) method has been used in various areas such as economy, virtual reality simulation in place of expert systems [24], sociology, or knowledge-based expert systems with the purpose of analysing the complex systems [25]. The developed cognitive maps method was first presented and used for modelling the causal relationship among the concepts by the authors of $[25,26]$. Prior to that, this method was introduced by a political scientist [27], for decision making in the social sciences and political areas. The mechanism of this method is based on replacing the actual values of concepts with fuzzy values [28-30]. On the basis of a specified scenario, the fuzzy-graph structure of FCM illustrates the parameters of the system by nodes or concepts, and the system characteristics, condition, and effects of parameters on each other are depicted by causal reasoning [25,26,31]. In actual fact, the structure of the FCM method works based on the combination of fuzzy logic and neural networks methods. The robust properties of both methods are evident in the FCM method [28,31].

The FCM structure is formed according to the requested outcome from the system [28]. Consequently, the FCM method has the potential to form as a nonlinear MIMO control system possibly even with some coupled parameters. Choosing the required and effective parameters from the system as nodes and assigning the suitable weights among them leads to the design of a convenient controller for the HVAC or A/C system. This method is able to keep the structure of the system like $\mathrm{MIMO}$, as well as coupled parameters; accordingly, an improvement in the accuracy and sensitivity of the controller can be obtained. Moreover, application of this control method on the nonlinear dynamic model of the system makes the results as similar as possible to the real results from the actual system. 
FCMs consist of concepts or nodes and edges between the nodes. The mathematical structure of FCM contains a $1 \times n$ state vector $(C)$ (it includes the values of the nodes) and an $n \times n$ weight matrix $\left(W_{i j}\right)$ (it includes the relationship between concepts), and the number of the nodes is shown by $n$ [32]. The value of every concept depends on the related concepts, with their weights and the concept's previous value. Value of nodes $\left(C_{i}\right)$ at a particular time reflect the activation degree of nodes in the system. The nodes values are attained by transformation of the real values of concepts into the interval $[0,1]$. Edges between the nodes $\left(W_{i j}\right)$ show the influence of each node on the other ones. Each weight gets a value in the range from -1 to $1[31,33] . W_{i j}>0$ shows the same effect of $C_{i}$ value on $C_{j}$ value. $W_{i j}=0$ depicts no relationship between $C_{i}$ and $C_{j} . W_{i j}<0$ shows an opposite effect of $C_{i}$ value on $C_{j}$ value $[23,28,31,33]$. Figure 8 indicates the diagram of the FCM method as a graph structure.

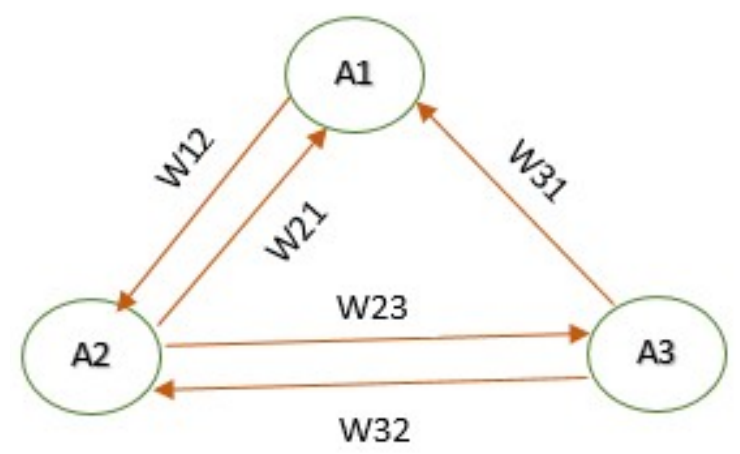

Figure 8. Schematic of the fuzzy cognitive map (FCM) method.

\section{MIMO Nonlinear Controller Based on FCM Method}

In order to design the controller for the DX/AC system according to the FCM method, the required concepts can be defined as follows [34]:

Concept 1: supply air temperature by evaporator $\left(T_{1}\right)$.

Concept 2: air conditioned room's temperature $\left(T_{2}\right)$.

Concept 3: supply humidity by evaporator $\left(W_{1}\right)$.

Concept 4: air conditioned room's humidity $\left(W_{2}\right)$.

Concept 5: supply fan flow rate (f).

Concept 6: compressor speed (S).

In spite of the advantageous of FCMs in design to control the complicated and complex nonlinear systems, the most considerable weak point of FCMs is their potential to converge to the undesired steady state. Thus, the initial weights were defined based on the predetermined information of the system around an operating point. Thus, to allocate proper initial weights for the FCM network, the generalized predictive control (GPC) method was chosen to find the minimum required values for control signals, which is suitable for the MIMO structure [20]. The relationships of concepts 1 to 4 were extracted from the direct and indirect relationships between the concepts in the linearized model of system. In other words, the matrixes $A$ and $B$ of the linearized model were applied to describe the concept weights. For the concepts where the relationship exists directly in matrix $A$ and $B$, the mentioned values were used as a direct relationship. For the other concepts with zero values, the indirect relations with the other concepts were considered and employed. For the actuators concepts, the relationships of them with other concepts are defined on the basis of the $K$ matrix calculation for the GPC model of the system. As the DX A/C system is MIMO, the steady space model of the system was employed for finding the $K$ matrix of the GPC model [31]. Regarding the use of these values as weights for the FCM method, they have to be normalized to the range of $[-1,1][34]$. 
Thus, the linearized dynamic model of the DX A/C system in state-space representation, which is more appropriate for designing MIMO control, can be written as Equation (9):

$$
\left\{\begin{array}{c}
\dot{X}=A x+B u \\
y=C x+d
\end{array}\right.
$$

where the output variables $y=\left[d T_{2}, d W_{2}\right]^{T}$ are the dynamic deviations of air-conditioned room temperature and humidity from their set points, respectively; and $A, B$, and $C$ are the coefficient matrices. According to the GPC method, the compact prediction notation is Equation (10) [35].

$$
\begin{aligned}
& \underset{\rightarrow}{x}=\underbrace{\left[\begin{array}{c}
A \\
A^{2} \\
\vdots \\
A^{n}
\end{array}\right]}_{P_{x}} x_{k}+\underbrace{\left[\begin{array}{cccc}
B & 0 & \cdots & 0 \\
A B & B & \cdots & 0 \\
\vdots & \vdots & \ddots & \vdots \\
A^{n-1} B & A^{n-2} B & \cdots & B
\end{array}\right]}_{H_{x}} \underbrace{\left[\begin{array}{c}
u_{k \mid k} \\
u_{k+1 \mid k} \\
\vdots \\
u_{k+n-1 \mid k}
\end{array}\right]}_{\stackrel{u}{\rightarrow}} \\
& \underset{\rightarrow k+1}{x}=P_{x} x_{k}+H_{x} \underset{\rightarrow k}{u} .
\end{aligned}
$$

The output predictions follow a similar method, as shown in Equation (11). The $P_{x}$ depends on past and the $H_{x}$ depends upon decision variables [35].

$$
\underset{\rightarrow k+1}{y}=\underbrace{\left[\begin{array}{c}
C A \\
C A^{2} \\
\vdots \\
C A^{n}
\end{array}\right]}_{P} x_{k}+\underbrace{\left[\begin{array}{cccc}
C B & 0 & \cdots & 0 \\
C A B & C B & \cdots & 0 \\
\vdots & \vdots & \ddots & \vdots \\
C A^{n-1} B & C A^{n-2} B & \cdots & C B
\end{array}\right]}_{H} \underbrace{\left[\begin{array}{c}
u_{k \mid k} \\
u_{k+1 \mid k} \\
\vdots \\
u_{k+n-1 \mid k}
\end{array}\right]}_{\stackrel{u}{\rightarrow}}+\underbrace{\left[\begin{array}{c}
d_{k} \\
d_{k} \\
\vdots \\
d_{k}
\end{array}\right]}_{L d}
$$

These are defined relative to an expected steady-state. Implicitly, their values assume a best estimate of the system disturbance, and of course knowledge of the desired target.

$$
\begin{aligned}
& r=y_{s s}=C x_{s s}+d_{k} ; \quad x_{s s}=A x_{s s}+B u_{s s} ; \\
& \hat{x}_{k}=x_{k}-x_{s s} ; \hat{u}_{k}=u_{k}-u_{s s} ; \\
& \left.\begin{array}{l}
\hat{x}_{k}=0 \\
\hat{u}_{k}=0
\end{array}\right\} \Rightarrow \hat{x}_{k+1}=A \hat{x}_{k}+B \hat{u}_{k}=0 ;
\end{aligned}
$$

The predictions are given as Equation (12) [35]:

$$
\stackrel{e}{\rightarrow}=\underset{\rightarrow}{\stackrel{\hat{y}}{\rightarrow}}=P_{x} \hat{x}_{k}+H_{k} \underset{\rightarrow}{\stackrel{\wedge}{u}} .
$$

Finally, by minimising the performance index and rewriting in terms of the actual state and input, one gets Equation (13) [35]:

$$
u_{k}-u_{S S}=-\underbrace{E_{1}^{T}\left[H_{x}^{T} Q H_{x}+R\right]^{-1} H_{x}^{T} Q P_{x}}_{K}\left[x_{k}-x_{S S}\right] .
$$


By minimizing the $\left(u_{k}-u_{s s}\right)$, the least control efforts to reach to the defined set points are calculated. Equations (14)-(16) show the finalized equations for finding the minimization of performance index. Entire values should normalize into the interval $[-1,1]$.

$$
\begin{gathered}
X_{k+1}-X_{s s}=A\left(X_{k}-X_{s s}\right)+B\left(u_{k}-u_{s s}\right) \\
Y_{k}-Y_{s s}=C\left(X_{k}-X_{s s}\right) \\
u_{k}-u_{s s}=-K\left(X_{k}-X_{s s}\right)
\end{gathered}
$$

Table 1 shows the numerical values and operating point of the DX A/C system based on the works of $[3,4,22,34]$, which are used for making the matrices $A, B, C$, and $K$ using the GPC method for weight matrix values between the concepts [34].

Table 1. Operating condition and numerical values of the system.

\begin{tabular}{cccccc}
\hline$T_{1}$ & $13.25^{\circ} \mathrm{C}$ & $W_{2}$ & $11.35 \mathrm{~g} / \mathrm{kg}$ dry air & $W_{1}$ & $9.03 \mathrm{~g} / \mathrm{kg}$ dry air \\
\hline$T_{2}$ & $24{ }^{\circ} \mathrm{C}$ & $p_{c}$ & $1.812 \times 10^{6} \mathrm{pa}$ & $Q_{\text {load }}$ & $4.49 \mathrm{kw}$ \\
\hline$T_{3}$ & $17^{\circ} \mathrm{C}$ & $p_{e}$ & $0.486 \times 10^{6} \mathrm{pa}$ & $s$ & $3960 \mathrm{rpm}$ \\
\hline$T_{w}$ & $13^{\circ} \mathrm{C}$ & $M$ & $0.96 \mathrm{Kg} / \mathrm{s}$ & $f$ & $0.347 \mathrm{~m}^{3} / \mathrm{s}$ \\
\hline$A_{1}$ & $4.14 \mathrm{~m}^{2}$ & $C_{\mathrm{p}}$ & $1.005 \mathrm{Kj} / \mathrm{kg}$ & $\mathrm{V}$ & $77 \mathrm{~m}^{3}$ \\
\hline$A_{2}$ & $17.65 \mathrm{~m}^{2}$ & $\rho$ & $1.2 \mathrm{~kg} / \mathrm{m}^{3}$ & $h_{f g h}$ & $2450 \mathrm{Kj} / \mathrm{kg}$ \\
\hline
\end{tabular}

The links among concepts are as follows [34]:

Connection 1: Connection of concept $1\left(T_{1}\right)$ to concept $1\left(T_{1}\right)$ with negative effect.

Connection 2: Connection of concept $1\left(T_{1}\right)$ to concept $3\left(W_{1}\right)$ with positive effect.

Connection 3: Connection of concept $1\left(T_{1}\right)$ to concept $4\left(W_{2}\right)$ with positive effect.

Connection 4: Connection of concept $1\left(T_{1}\right)$ to concept $5(f)$ with positive effect.

Connection 5: Connection of concept $1\left(T_{1}\right)$ to concept $6(S)$ with positive effect.

Connection 6: Connection of concept $2\left(T_{2}\right)$ to concept $1\left(T_{1}\right)$ with positive effect.

Connection 7: Connection of concept $2\left(T_{2}\right)$ to concept $2\left(T_{2}\right)$ with negative effect.

Connection 8: Connection of concept $2\left(T_{2}\right)$ to concept $5(f)$ with negative effect.

Connection 9: Connection of concept $2\left(T_{2}\right)$ to concept $6(S)$ with positive effect.

Connection 10: Connection of concept $3\left(W_{1}\right)$ to concept $1\left(T_{1}\right)$ with positive effect.

Connection 11: Connection of concept $3\left(W_{1}\right)$ to concept $6(S)$ with positive effect.

Connection 12: Connection of concept $4\left(W_{2}\right)$ to concept $3\left(W_{1}\right)$ with positive effect.

Connection 13: Connection of concept $4\left(W_{2}\right)$ to concept $4\left(W_{2}\right)$ with negative effect.

Connection 14: Connection of concept $4\left(W_{2}\right)$ to concept $5(f)$ with negative effect.

Connection 15: Connection of concept $4\left(W_{2}\right)$ to concept $6(S)$ with positive effect.

Connection 16: Connection of concept $5(f)$ to concept $1\left(T_{1}\right)$ with positive effect.

Connection 17: Connection of concept $5(f)$ to concept $2\left(T_{2}\right)$ with negative effect.

Connection 18: Connection of concept $5(f)$ to concept $3\left(W_{1}\right)$ with positive effect.

Connection 19: Connection of concept $5(f)$ to concept $4\left(W_{2}\right)$ with negative effect.

Connection 20: Connection of concept $5(f)$ to concept $5(f)$ with positive effect.

Connection 21: Connection of concept $6(S)$ to concept $1\left(T_{1}\right)$ with positive effect.

Connection 22: Connection of concept $6(S)$ to concept $2\left(T_{2}\right)$ with positive effect.

Connection 23: Connection of concept $6(S)$ to concept $3\left(W_{1}\right)$ with positive effect.

Connection 24: Connection of concept $6(S)$ to concept $4\left(W_{2}\right)$ with positive effect.

Connection 25: Connection of concept $6(S)$ to concept $6(S)$ with positive effect.

Figure 9 illustrates the graph structure of the controller [34]. 


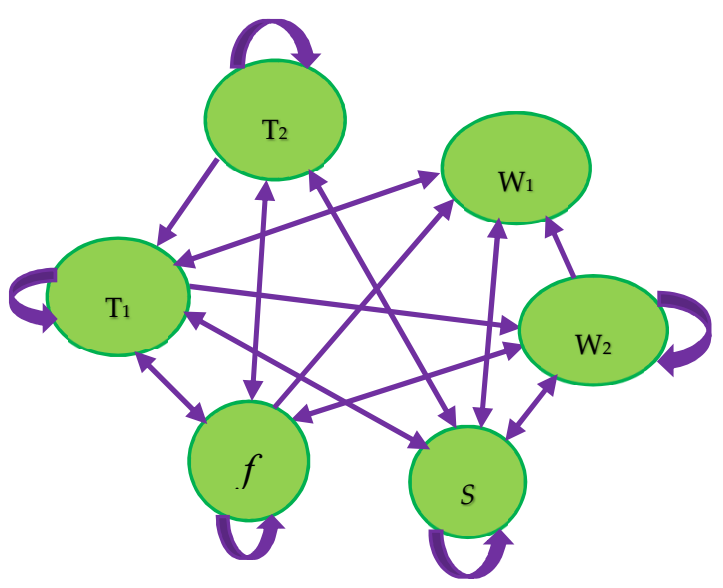

Figure 9. Schematic of graphical structure of the FCM controller.

This graphical structure of the controller follows the simple mathematical model of FCM, which contains a $1 \times \mathrm{n}$ state vector $(C)$, which is the values of the $\mathrm{n}$ concepts, and an $n \times n$ weight matrix, which is the weights $\left(W_{i j}\right)$ between the concepts. The number of concepts is six [32,34,36]. On the basis of the construction of FCMs, all nodes' real values are normalized in the range [0, 1] by Equation (17) as a transformation mechanism. Next, Equations (18) and (19) are employed for calculation of concepts activation level $\left(C_{i}\right)$ for every concept $[23,32,34,36]$. Lastly, Equations (18) and (19) were continued until the values do not change at all, and the control signal values were defuzzified and applied to the actuators [34].

$$
\begin{gathered}
g\left(S_{i}^{t}\right)\left\{\begin{array}{cc}
0, & \text { if } S_{i}{ }^{t}<a_{i} \\
\left(S_{i}{ }^{t}-a_{i}\right) /\left(2\left(m_{i}-a_{i}\right)\right), & \text { if } a_{i} \leq S_{i}{ }^{t}<m_{i} \\
0.5+\left(S_{i}^{t}-m_{i}\right) /\left(2\left(b_{i}-m_{i}\right)\right), & \text { if } \mathrm{m}_{i}<S_{i}{ }^{t} \leq b_{i} \\
1, & \text { if } S_{i}{ }^{t}>b_{i}
\end{array}\right. \\
C_{i}^{\text {new }}=f\left(\Sigma C_{j}^{\text {old }} \times W_{i j}\right)+C_{i}^{\text {old }} \\
f(x)=\frac{1}{\left(1+e^{-\lambda x}\right)}
\end{gathered}
$$

The detected values of the $i$ th state at time $t$, max, min, and mean are shown by $S_{i}^{t}, b_{i}, a_{i}$, and $m_{i}$, respectively. $C_{i}^{\text {new }}$ depicts the activation level of concept $i$ at time $t+1$ and $C_{j}^{\text {cold }}$ discloses the activation level of concept $j$ at time $t$. The threshold function is shown by $f$.

FCM has been widely used in practice, mainly owing to its capabilities to deal with complex nonlinear systems. On the other hand, crucially big steady state error is one of the disadvantages of the FCM technique. To solve the aforementioned problem, one can deploy learnability of FCM. Updating the weights by applying supervised learning techniques on FCM makes the FCM technique more practical for online real-time control problems. Herein, the following supervised $\delta$ learning rules were chosen:

$$
\begin{gathered}
W_{i j}(K+1)=W_{i j}(K)+\Delta W_{i j}(K), \\
\Delta W_{i j}(K)=\eta A_{i}(K) C_{j}(K)\left(1-C_{j}(K)\right)\left(d_{j}-C_{j}(K)\right) .
\end{gathered}
$$

The expected value of input node $j$ is $d_{j}$; the state value of the nodes connected to this input node is $C_{i}$; the state value of input node $j$ is $C_{j}$; the learning rate is $\eta$, which it is in the range $[0,1]$; and the iteration step is $K$. The concepts' preferred values should be placed in matrix $d$. 


\section{Stability Analysis of Fuzzy Cognitive Map Method}

On the basis of the work of [37], the stability analysis test for the FCM method as a core control method on complex nonlinear MIMO systems should be done by considering the FCM as a one layer network fuzzy bidirectional associative memories (FBAMs). In other words, it can be taken into account as a special case of FBAMs, which has a one-layer network rather than a two-layer network. The FBAM is a two-layer neural network with two layers of $X$ and $Y$, where matrix $P$ displays the connection matrix from $X$ layer to $Y$ layer, and $R$ matrix specifies the connection matrix from $Y$ layer to $X$ layer. The number of fuzzy neurons are shown by $n$ and $m$ in the layers of $X$ and $Y$, respectively. The stability analysis of FBAMs is justified by applying the triangular norms [38]. Triangular norms ( $T$-norms) and $T$-conorm ( $S$-norm) generalize the AND operation and the OR operation for fuzzy system respectively. Any FBAM based on the $S-T$ composition is globally stable, if and only if the FBAMs are globally stable when the connection matrices are based on the max- $T$ composition, and the product of $S-T$ composition of them is convergent to the max- $T$ composition. This means that global stability of FBAMs is dependent on the matrix power convergence. In contrast, FCM is a one-layer network with one weight matrix. By decomposing the weight matrix $(W)$ to the two triangular matrices, it can be transferred to the two layer structure for stability analysis as follows [37]:

$$
W=L \cdot U
$$

The FCM weight matrix can be decomposed by the LU factorization method or the Gaussian elimination method. These methods show the matrix $W$, which is square, as a product of a permutation of a lower triangular matrix $(L)$, with ones on its diagonal and an upper triangular matrix $(U)$. If diagonal elements of $L$ or $U$ are non-zero, then such a factorization is unique for the given $W$. For being factorized into two matrices $L$ and $U$, the weight matrix $W$ for the given FCM must satisfy the following condition. As the weight matrix is a fuzzy matrix, it always has non-zero elements because of the interconnection of the parameters and its influence directly and indirectly through the other parameters on each other and, accordingly, non-zero principal minors. Thus, it can always be decomposed into two triangular matrices. By transforming the FCM structure to two-layer as layer $\mathrm{G}$ and layer $\mathrm{H}$, the relationship between the layers is presented by two factorized matrices. The $L$ matrix indicates the relationship between layer $\mathrm{G}$ and layer $\mathrm{H}$, and the $U$ matrix shows the relationship between layer $\mathrm{H}$ and layer $\mathrm{G}$. Both layers have the same number of concepts as FCM concepts. Figure 10 illustrates the transformation of the FCM method to two-layer as layer G and H [37].

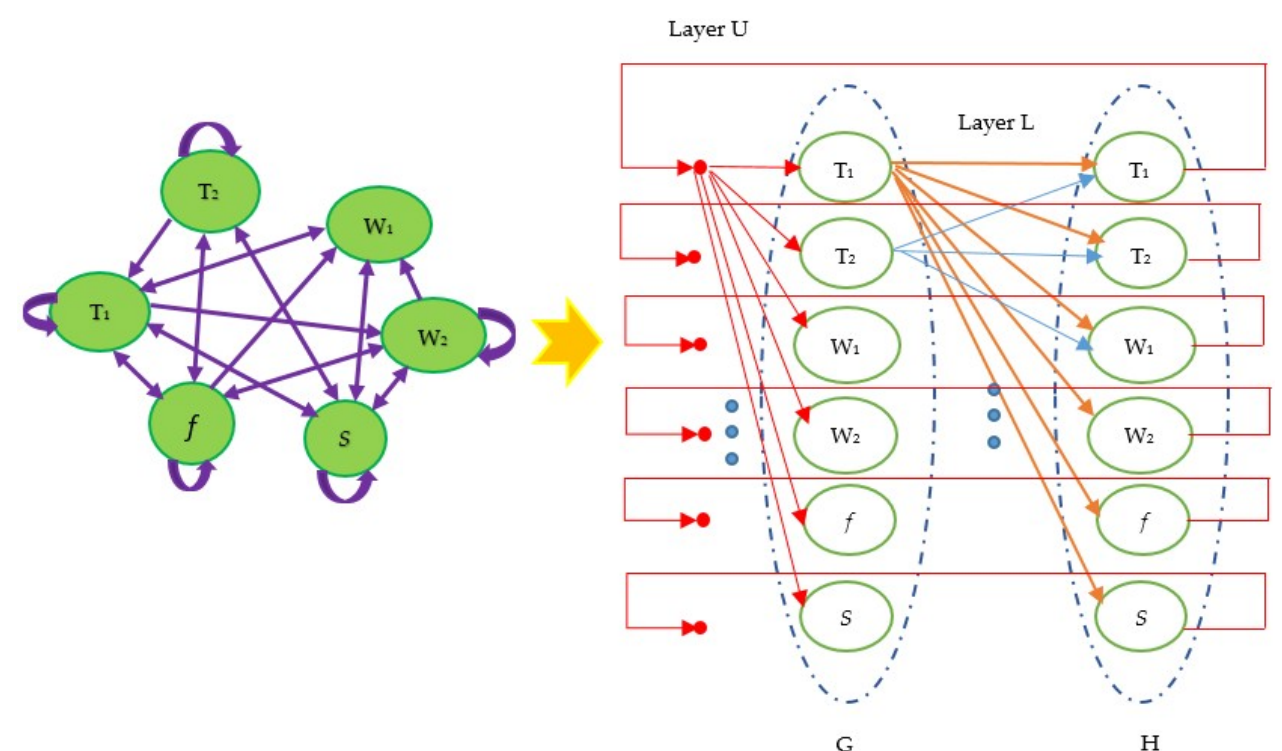

Figure 10. Transformation of the FCM method to two layers. 
The new style of FCM is written as follows:

$$
\left\{\begin{array}{l}
G^{(k+1)}=\left(G^{(k)} \cdot L\right) \cdot U \\
H^{(k+1)}=\left(H^{(k)} \cdot U\right) \cdot L
\end{array} .\right.
$$

For FCM stability analysis, a specific $T$-norm should exist, which is obtained from the $S-T$ composition of the triangular matrices from decomposition of the weight matrix. For this matter, this T-norm should be equal to the original weight matrix. If this $S$-T composition exists, the FCM is globally stable. The product of the $S$-T composition for two matrices $L=\left(l_{i j}\right)_{m \times p}$ and $U=\left(u_{i j}\right)_{p \times n}$ should be as follows [37]:

$$
L \bigcirc U=\left(w_{i j}^{\prime}\right),
$$

where

$$
w_{i j}^{\prime}=\left(l_{11} T u_{1 j}\right) S\left(l_{i 2} T u_{2 j}\right) S . . . S\left(l_{i p} T u_{p j}\right) .
$$

In other words, the following steps should be done for the stability analysis of FCMs:

1. Factorization of weight matrix to $L$ and $U$ matrices;

2. Getting a product of $S$ - $T$ composition for $L$ and $U$ matrices based on Equation (25);

3. If such an $S-T$ composition exists for the $L$ and $U$ matrices, which is equal to $W$, then the assumed FCM structure is globally stable; otherwise, the proposed stability method cannot solve the stability problem of the assumed FCM method [37].

Following the above processes and the values from Table 1, the weight matrix and factorization to the matrix $L$ and $U$ for the proposed designed controller are as below. Accordingly, the designed controller is globally stable.

$$
\begin{aligned}
W & =\left[\begin{array}{cccccc}
-0.279 & 0.9 & 0.6 & 0 & 0.9295 & 0.94095 \\
0 & -0.9 & 0 & 0 & -0.26662 & 0.2267 \\
0.63795 & 0 & 0 & 0.45 & 0.7707 & 0.85448 \\
0.63795 & 0 & 0 & -0.9 & -0.7707 & 0.99689 \\
0.4238 & -0.417 & 0 & -0.7 & 1 & 0 \\
0.3471 & 0.4686 & 0.84 & 0.98 & 0 & 1
\end{array}\right], \\
L & =\left[\begin{array}{ccccccc}
-0.43734 & 0 & 0 & 0 & 0 & 0 \\
0 & 1 & 0 & 0 & 0 & 0 \\
1 & & 0 & 0 & 0 & 0 & 0 \\
1 & 0 & 0 & 1 & 0 & 0 \\
0.66432 & 0.46333 & 0 & 0.73996 & 0.98796 & 0 \\
0.54409 & -0.52067 & 1 & 0 & 0 & 0
\end{array}\right] \\
U & =\left[\begin{array}{ccccccc}
0.63795 & 0 & 0 & 0.45 & 0.7707 & 0.85448 \\
0 & -0.9 & 0 & 0 & -0.26662 & 0.2267 \\
0 & 0 & 0.84 & 0.73516 & -0.55815 & 0.65312 \\
0 & 0 & 0 & -1.35 & -1.5414 & 0.14241 \\
0 & 0 & 0 & 0 & 1.7735 & 1.0402 \\
0 & 0 & 0 & 0 & 0 & -1.8057
\end{array}\right] .
\end{aligned}
$$

Proof of stability analysis by the Lyapunov direct method can be written as below for the fuzzy cognitive map control method. Lyapunov design refers to the synthesis of control laws for the desired closed-loop stability properties, using the Lyapunov function for the mentioned nonlinear control system as follows [39,40]:

$$
\dot{x}=f(x ; u(x)),
$$


where $x \in R^{n}$ is the state and $u \in R^{m}$ is the control input. As a result, Equation (11) can be written in the following form [41]:

$$
C_{i}(x)\left\{\begin{array}{cc}
C_{i}=f\left(\sum C_{j}(x) w_{i j}(x)\right), & \text { for } \mathrm{x}=0 \\
C_{i}(x)=f\left(C_{i}(x-1)+\sum C_{j}(x) w_{i j}(x)\right), & \text { for } \mathrm{x} \neq 0
\end{array} .\right.
$$

The $f(x)$ is the unipolar sigmoid threshold function as Equation (15), which squashes the values in the range of 0 to 1 . As the fuzzy cognitive map is a nonlinear dynamical system, the system operates in the form of dynamics. As a result, the system can be evaluated in the way of the energy function reduction direction, and it reached a stable state. Therefore, a Lyapunov function for fuzzy cognitive map, which is called the energy function, by considering the $f$ function as the $S$ shaped continuous function like Equation (15), can be written as follows [41]:

$$
E(t)=-\frac{1}{2} \sum_{i=1}^{n} \sum_{j=1}^{n} w_{i j} f_{i}(x) f_{j}(x)-\sum_{i=1}^{n} \int_{0}^{f_{i}(x)} f^{-1}(x) d x .
$$

As for the activation function $f(x)$, the $S$-type threshold function is used. The energy function is bounded defined above, consequently, only proving of the $\frac{d E}{d x}$ will show the stability of the system.

$$
\frac{d E}{d t}=\sum_{i=1}^{n} \frac{\partial E}{\partial f_{i(x)}} \frac{\partial f_{i(x)}}{\partial t}
$$

The partial derivative is extracted from Equation (24) as follows:

$$
\frac{\partial E}{\partial f_{i(x)}}=-\sum_{j=1}^{n} w_{i j} f_{j}(x)+f^{-1}(x) .
$$

By combining Equations (29) and (30), Equation (29) can be rewritten as follows:

$$
\frac{d E}{d t}=-\sum_{i=1}^{n}\left(\sum_{j=1}^{n} w_{i j} f_{j}(x) \frac{d f_{i(x)}}{d t}+\left(\frac{d f_{i(x)}}{d t}\right)^{2} .\right.
$$

Because of the choice of the $S$-type threshold function, which is monotonic type as an activation function, the function is increasing. It is clear that its inverse function $f^{-1}(x)$ is also a monotonic type and increasing function. Therefore, the value $\frac{d f_{i(x)}}{d t} \geq 0$, so that $\frac{d E}{d t} \leq 0$. It is proven that the fuzzy cognitive map must be stable based on Lyapunov's theory [39,40].

\section{Performance Analysis Test and Results}

In order to performance validation of the designed control system, two performance measures are taken into account, namely reference tracking and disturbance rejection. Simulation was done in MATLAB/Simulink (R2017b, The MathWorks, Inc, Natick, MA, USA) and the results are presented below.

\subsection{Reference Tracking}

The reference tracking results emphasize the ability of the controller to stabilize the system to the new reference signal. To mimic tropical regions (i.e., Malaysia conditions), the mean temperature of $30{ }^{\circ} \mathrm{C}$ and mean humidity ratio of $80 \%$ were chosen for this simulation. The results clearly show that the comfort temperature and humidity based on tropical countries standards are obtained by the designed control system. Figure 11 displays the actual and reference of the air-conditioned room temperature. The reference temperature changed from $25^{\circ} \mathrm{C}$ to $23^{\circ} \mathrm{C}$ at $1300 \mathrm{~s}$. The set initial room temperature is $30^{\circ} \mathrm{C}$. It can be obviously seen that the temperature stabilized at the desired set points with settling 
times of 380 and $1325 \mathrm{~s}$, respectively. The air-conditioned room humidity is shown in Figure 12. The set initial room humidity is $80 \%$ or $0.02157 \mathrm{~kg} / \mathrm{Kg}$. It is clearly seen that the humidity stabilized at the desired set points, with settling times of 1200 and $1357 \mathrm{~s}$, respectively. The humidity declines from 80\% to $48 \%$ or $0.02157 \mathrm{~kg} / \mathrm{Kg}$ to $0.00948 \mathrm{~kg} / \mathrm{Kg}$ at about $1200 \mathrm{~s}$. After changing the set point at $1300 \mathrm{~s}$, the humidity reaches to $0.009977 \mathrm{~kg} / \mathrm{Kg}$ or $53.5 \%$ at $1357 \mathrm{~s}$ and stabilizes. The humidity is still in the tropical thermal comfort range, which is in the range of $40 \%$ to $60 \%$. The supply air temperature is depicted in Figure 13. The set initial supply air temperature is $11.25^{\circ} \mathrm{C}$. It is clear that the controller stabilized the supply air temperature at 180 and $1327 \mathrm{~s}$, respectively. After changing the set point, it increases at $1300 \mathrm{~s}$ to $15.85^{\circ} \mathrm{C}$ and then decreases gradually to $13.66^{\circ} \mathrm{C}$ at near $1327 \mathrm{~s}$ and is maintained. Figure 14 illustrates the supply humidity. The set initial supply humidity is $0.009 \mathrm{~kg} / \mathrm{Kg}$. It is evident that the controller stabilized the supply humidity at 1200 and $1329 \mathrm{~s}$, respectively. The humidity rises from $0.009 \mathrm{~kg} / \mathrm{Kg}$ to $0.01728 \mathrm{~kg} / \mathrm{Kg}$ at around $29 \mathrm{~s}$, becomes stable at $129 \mathrm{~s}$, and then declines to $0.006 \mathrm{~kg} / \mathrm{Kg}$ at almost $1200 \mathrm{~s}$, after which it increases a little to $0.006555 \mathrm{~kg} / \mathrm{Kg}$ and then stabilizes. After set point changing, the humidity increasingly changed to $0.009481 \mathrm{~kg} / \mathrm{Kg}$ at around $1329 \mathrm{~s}$, then decreased to $0.008754 \mathrm{~kg} / \mathrm{Kg}$ and maintained. The fan flow rate is illustrated in Figure 15. The set initial flow rate is $0.34 \mathrm{~m}^{3} / \mathrm{s}$. It is clear that the proposed controller stabilizes the flow rate at 1200 and $39 \mathrm{~s}$, respectively. It raises from $0.34 \mathrm{~m}^{3} / \mathrm{s}$ to $0.382 \mathrm{~m}^{3} / \mathrm{s}$ and stabilize at just about $1200 \mathrm{~s}$. After $1200 \mathrm{~s}$, it decreases rapidly to $0.325 \mathrm{~m}^{3} / \mathrm{s}$ and remains stable at $1300 \mathrm{~s}$. As a result of set point changing at $1300 \mathrm{~s}$, it is sharply increased to $0.8815 \mathrm{~m}^{3} / \mathrm{s}$, then dropped and finally stabilizes at $0.34 \mathrm{~m}^{3} / \mathrm{s}$ at around $1339 \mathrm{~s}$ and maintained. The compressor speed is demonstrated in Figure 16. The set initial compressor speed is $3000 \mathrm{rpm}$. It is obviously seen that the controller is able to stabilize the compressor speed at 1200 and $1334 \mathrm{~s}$, respectively. The speed raises from $3000 \mathrm{rpm}$ to $6359 \mathrm{rpm}$, and becomes more or less stable around $6320 \mathrm{rpm}$. Afterward, at around $1200 \mathrm{~s}$, it declined to $3960 \mathrm{rpm}$. From $1300 \mathrm{~s}$, the speed moved upwards to $6326 \mathrm{rpm}$, and from $1327 \mathrm{~s}$, it leveled off and maintained at $3180 \mathrm{rpm}$ at $1334 \mathrm{~s}$.

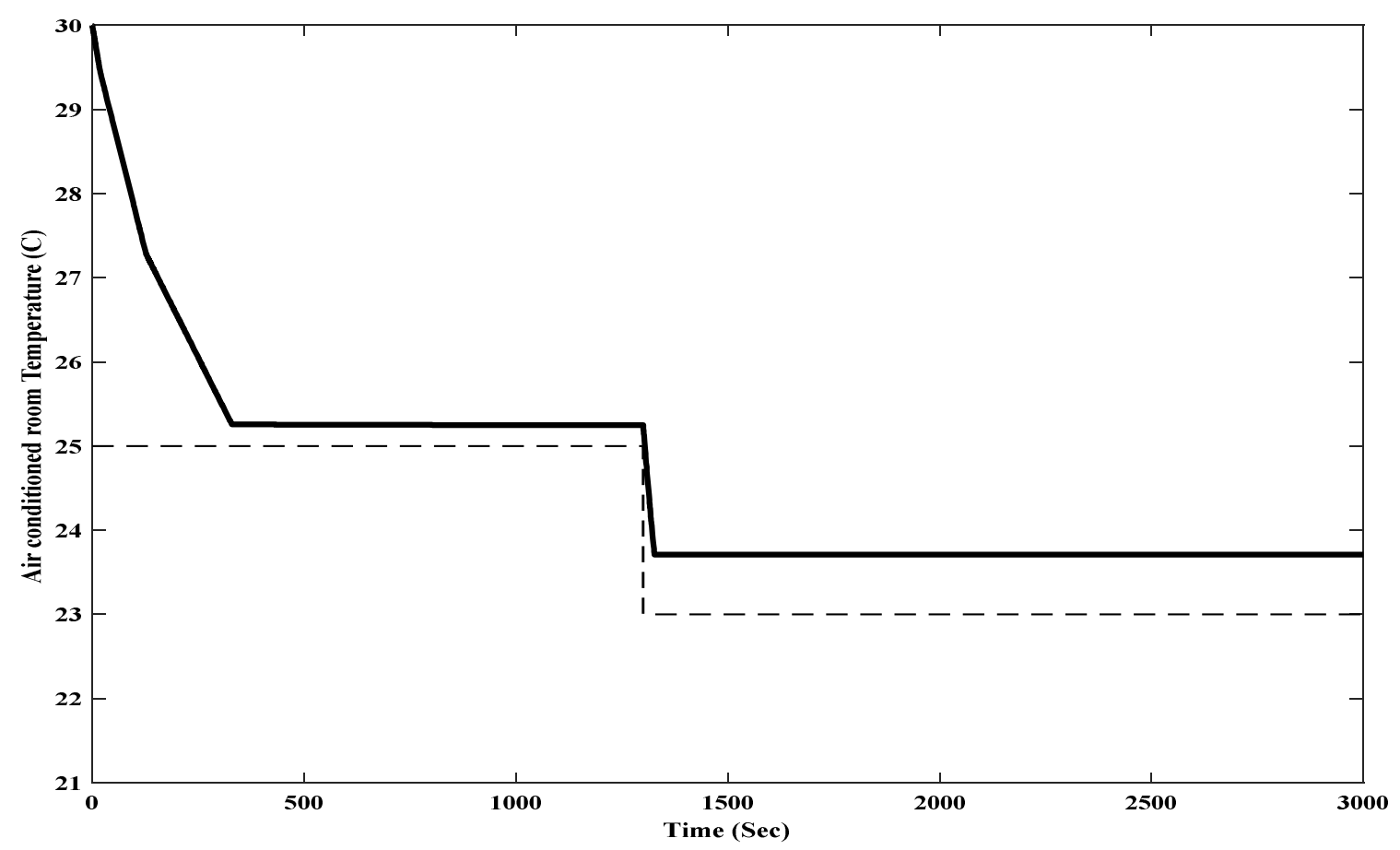

Figure 11. Temperature of the air-conditioned room in set point changing. 


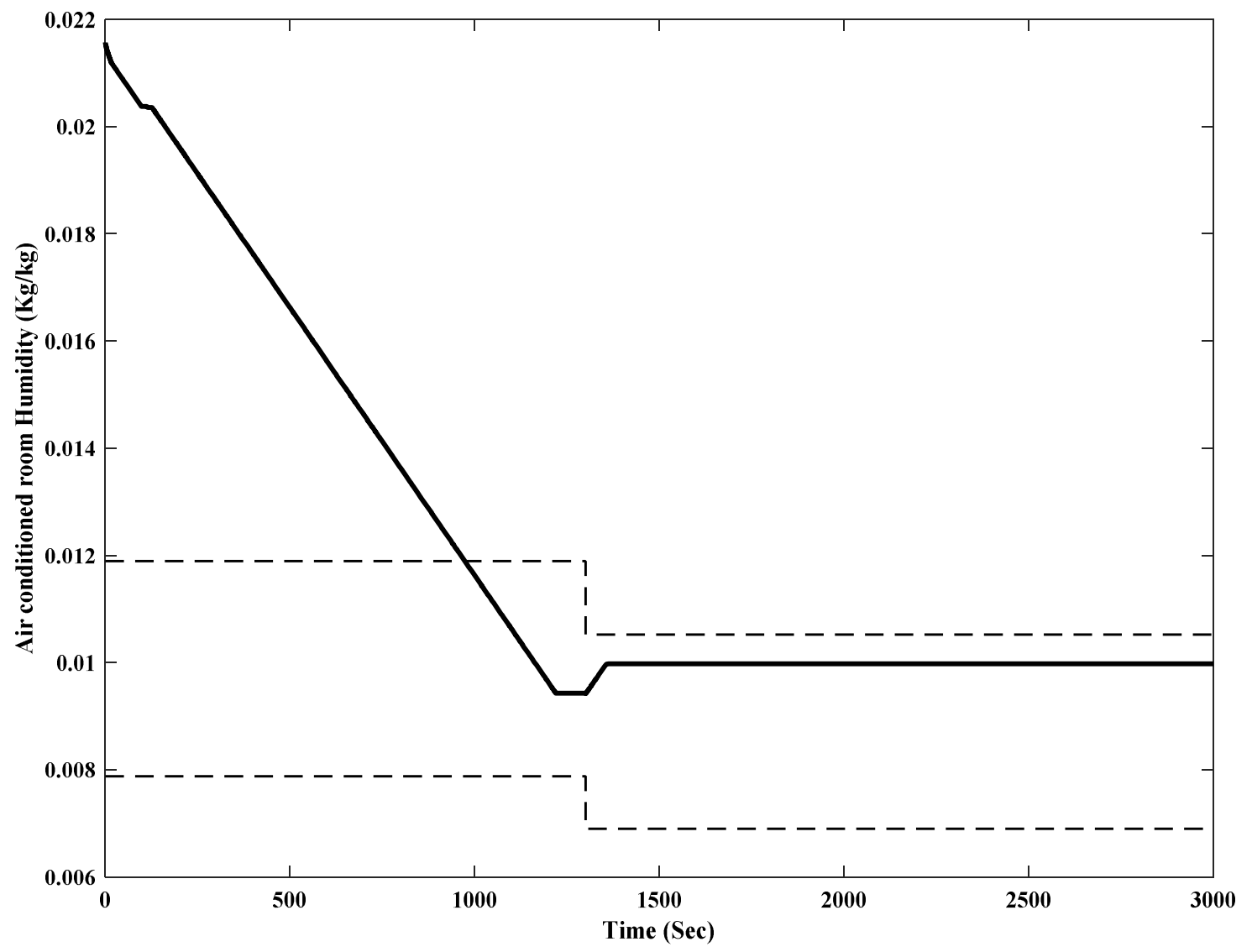

Figure 12. Humidity of the air-conditioned room in set point changing.

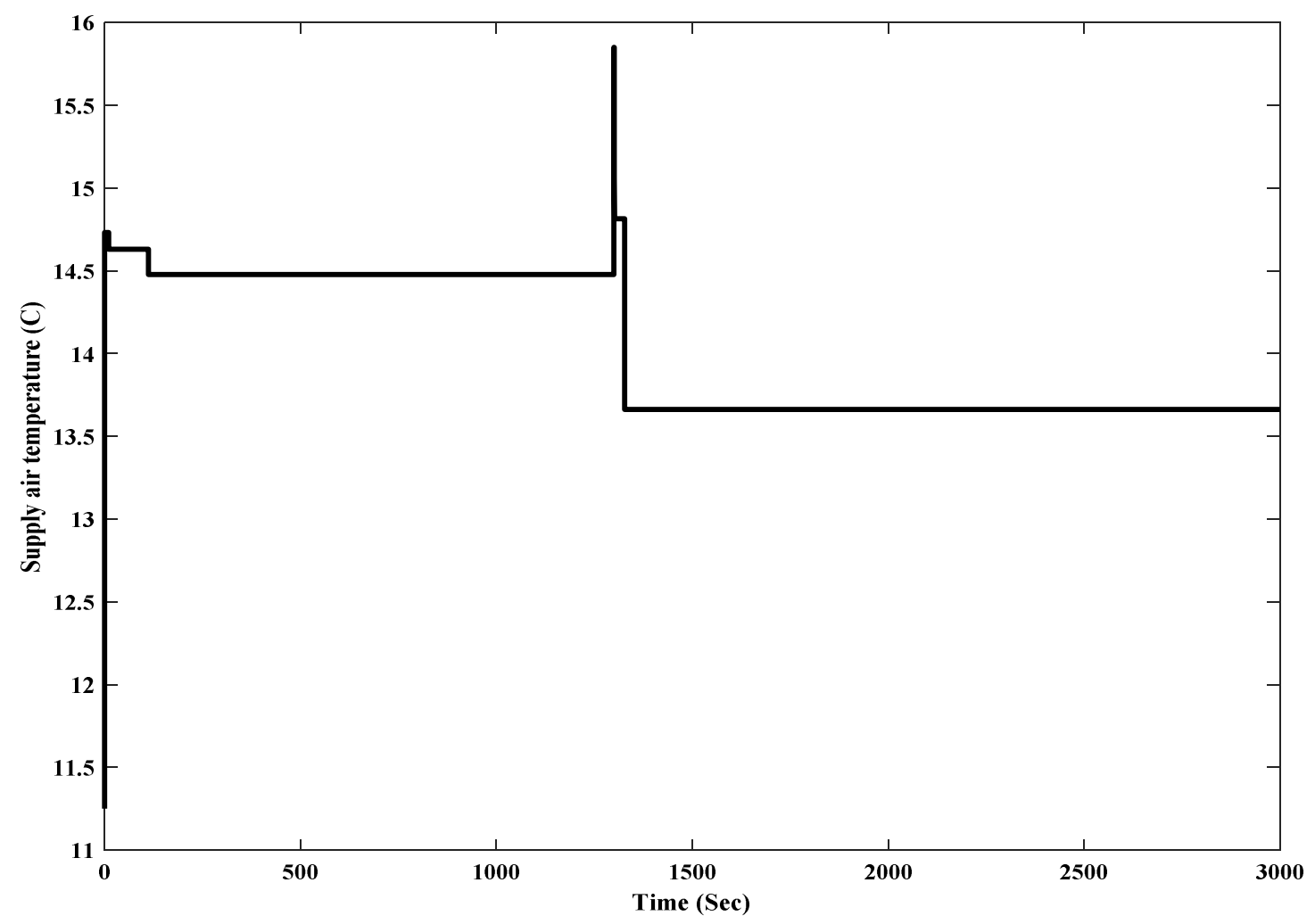

Figure 13. Supply temperature exit from evaporator in set point changing. 


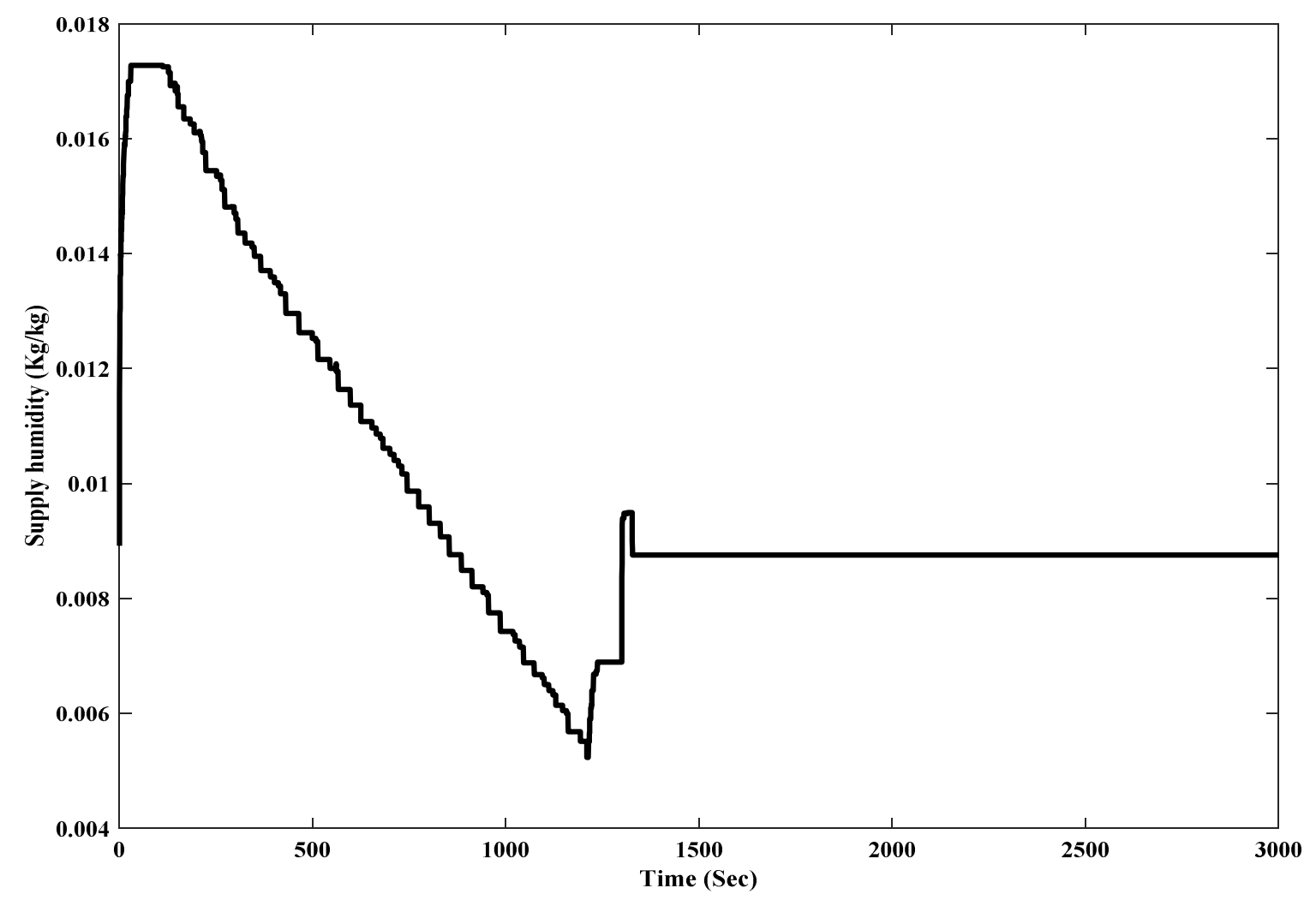

Figure 14. Supply humidity exit from evaporator in set point changing.

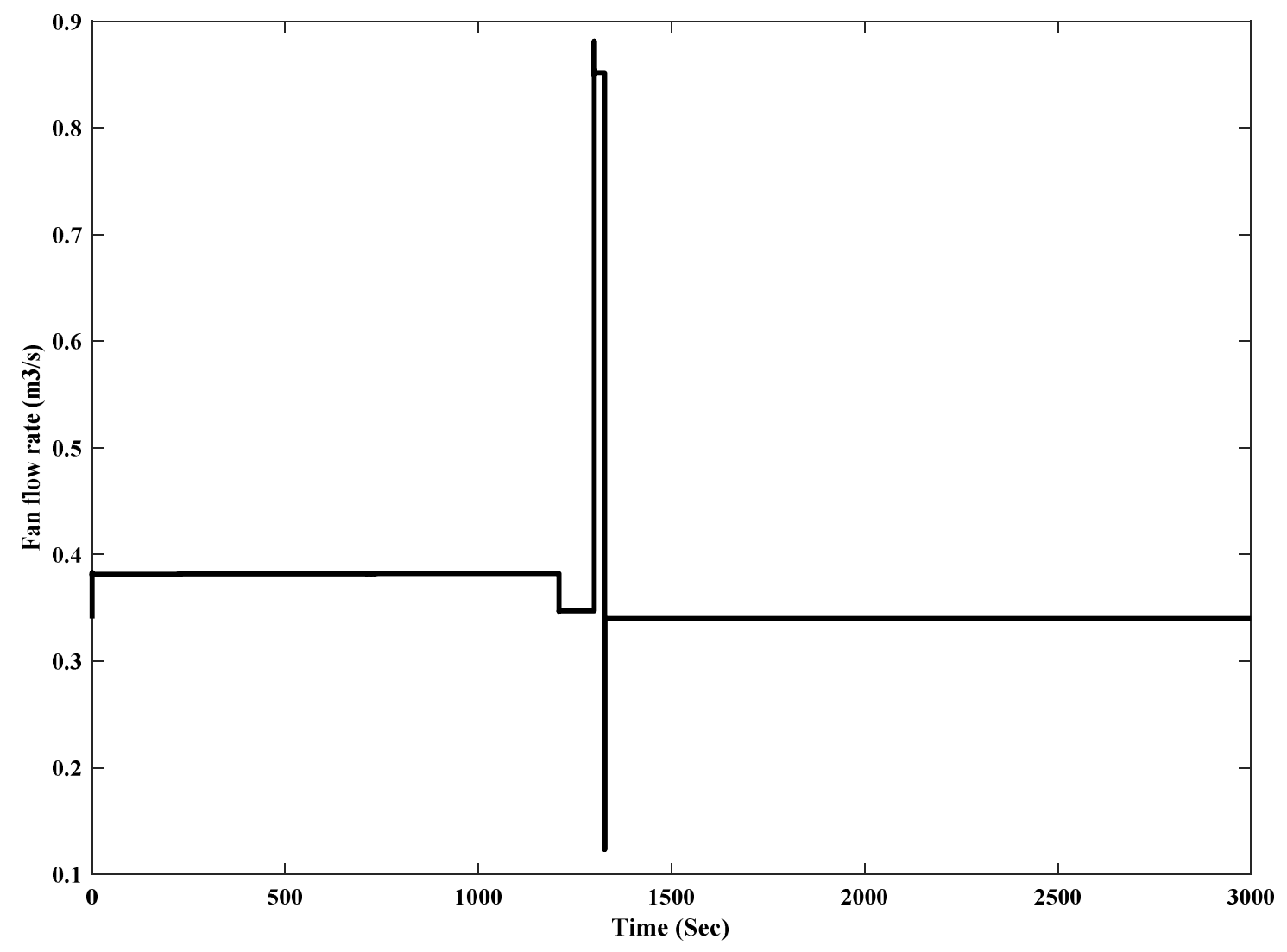

Figure 15. Supply flow rate by fan in set point changing. 


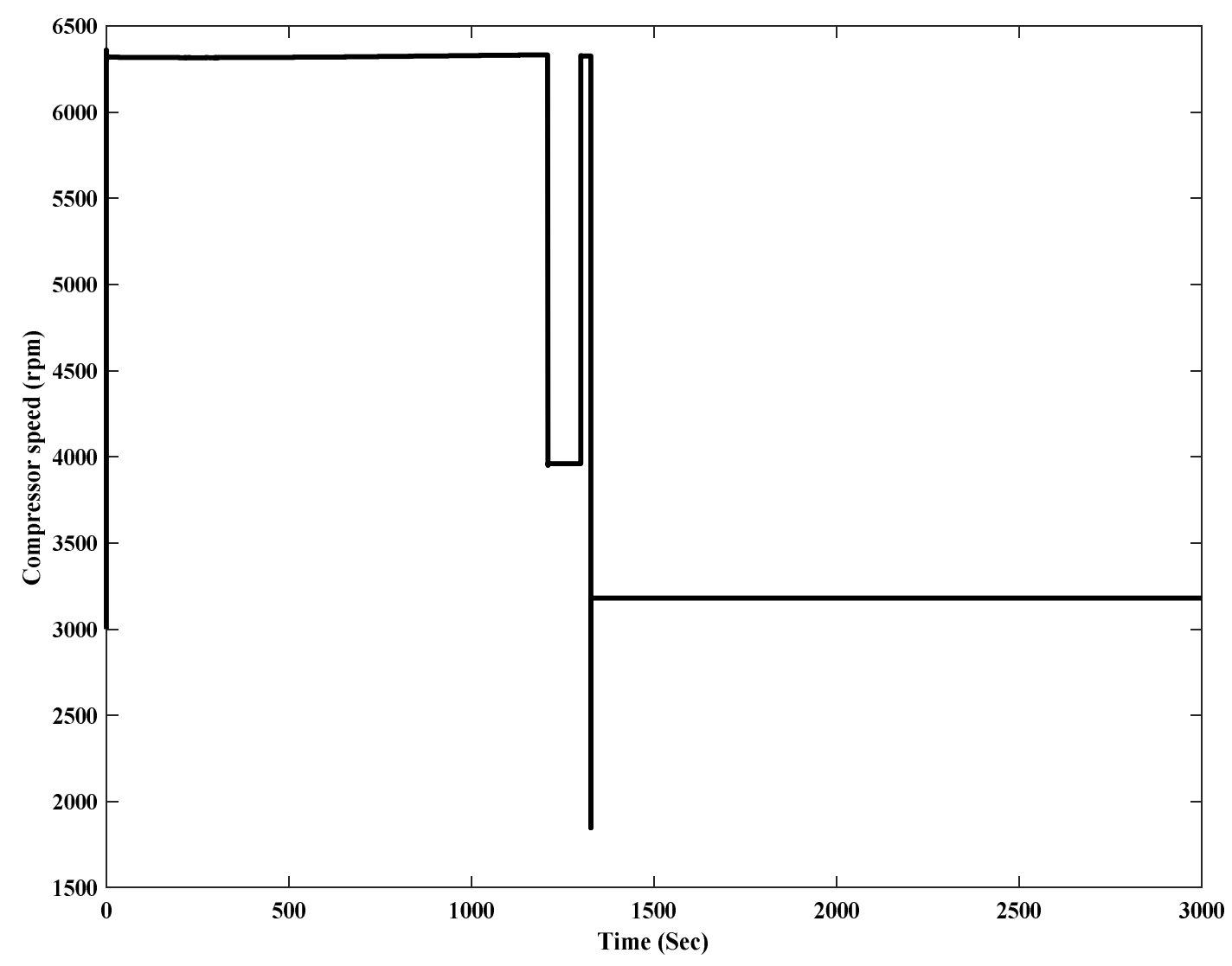

Figure 16. Compressor speed in set point changing.

\subsection{Disturbance Rejection}

The disturbance rejection test results emphasize the controller qualification for controlling the situation and maintaining the system outputs in preferred set points during the occurrence of disturbances. In this situation, changing the flow rate of the fan and speed of compressor allows for controlling the situation of the air-conditioned room temperature and humidity, and maintaining them at preferred set points. In order to test the disturbance rejection ability of the controller, at $2000 \mathrm{~s}$, the heat load changed from $4.49 \mathrm{~kW}$ to $5.49 \mathrm{~kW}$ and moisture load changed from $0.96 \mathrm{Kg} / \mathrm{s}$ to $1.6 \mathrm{Kg} / \mathrm{s}$. The temperature of the air-conditioned room in disturbance rejection test is indicated in Figure 17. At $2000 \mathrm{~s}$, the temperature of the air-conditioned room increased gradually; then at around $2050 \mathrm{~s}$, the temperature declined slowly; and finally, at $2100 \mathrm{~s}$, it stabled at $25.6{ }^{\circ} \mathrm{C}$, which is in the thermal comfort range. As indicated in Figure 18, the humidity of the air-conditioned room went up gradually from $0.009863 \mathrm{~kg} / \mathrm{Kg}$ at $2000 \mathrm{~s}$ to $0.01008 \mathrm{~kg} / \mathrm{Kg}$ at around $2050 \mathrm{~s}$, then it picked up to $0.0101 \mathrm{~kg} / \mathrm{Kg}$ and then stabilized. Figure 19 shows the supply air temperature, which sharply reached $14.73{ }^{\circ} \mathrm{C}$ in $4.03 \mathrm{~s}$, and then became stable until $2054 \mathrm{~s}$, where it sharply increased to $14.87^{\circ} \mathrm{C}$ and maintained. Supply humidity increased to $0.007986 \mathrm{~kg} / \mathrm{Kg}$ from $2000 \mathrm{~s}$ to $2061 \mathrm{~s}$, and then decreased gradually to 0.007735 at $2111 \mathrm{~s}$ and stabilized. Figure 20 illustrates the supply humidity. In Figure 21, the supply fan flow rate indicates that at $2000 \mathrm{~s}$, the flow rate by fan went upwards sharply from $0.341 \mathrm{~m}^{3} / \mathrm{s}$ to $0.4595 \mathrm{~m}^{3} / \mathrm{s}$ from $2046 \mathrm{~s}$ to $2066 \mathrm{~s}$ and maintained. Figure 22 shows the speed of the compressor, which increases from $4140 \mathrm{rpm}$ to $6332 \mathrm{rpm}$ at $2054 \mathrm{~s}$ to about $2066 \mathrm{~s}$ and stabilized. 


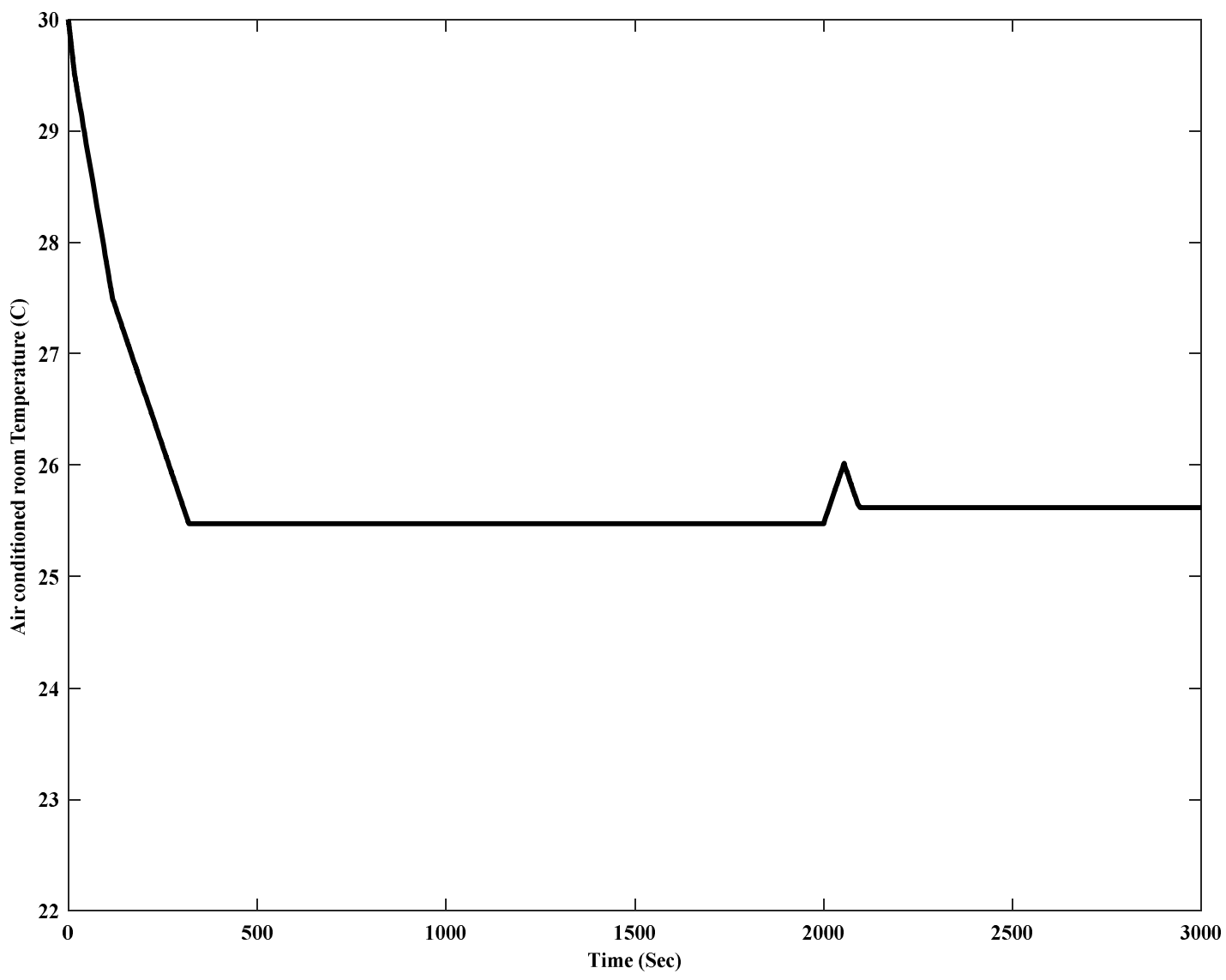

Figure 17. Temperature of the air-conditioned room in a disturbance rejection test.

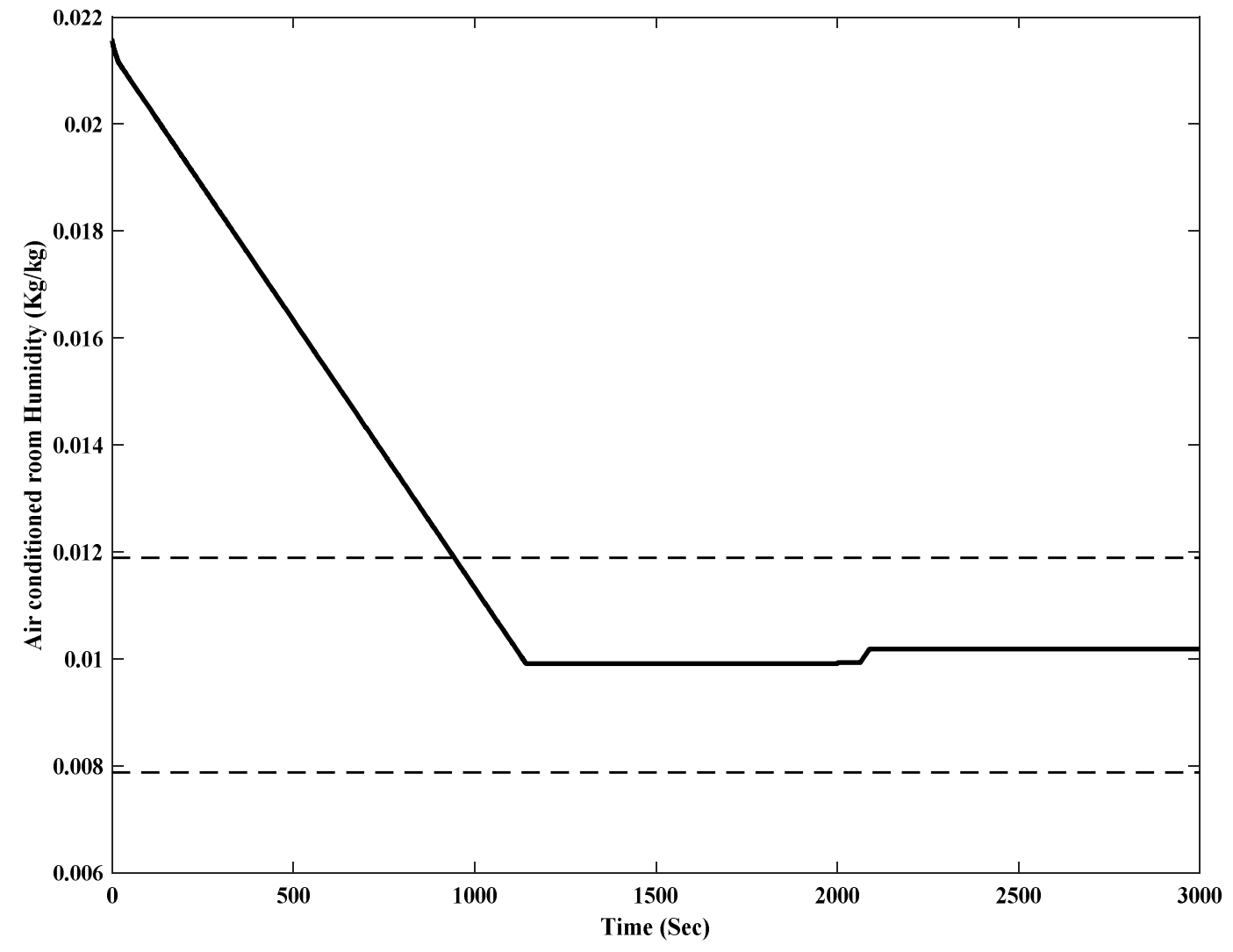

Figure 18. Humidity of the air-conditioned room in a disturbance rejection test. 


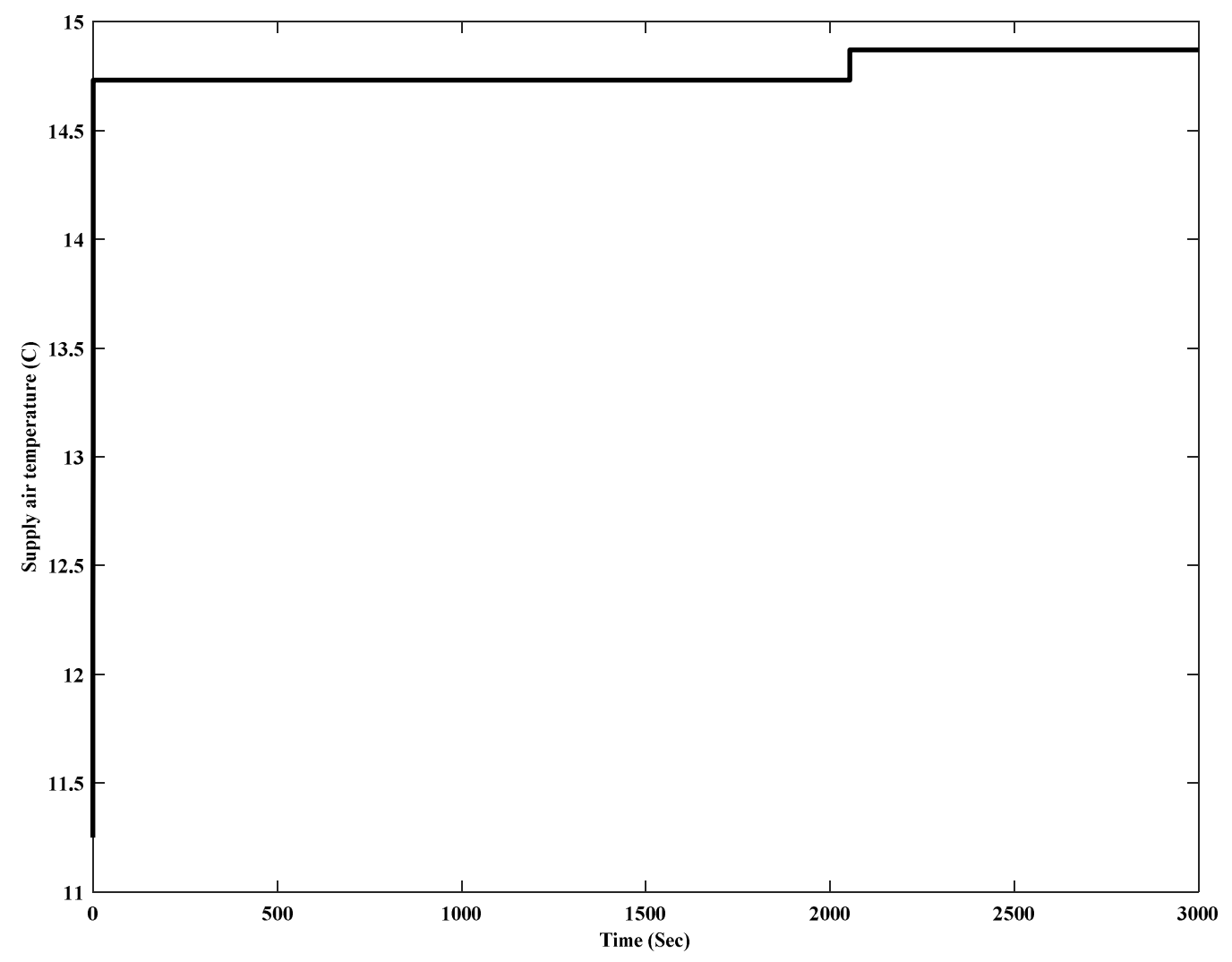

Figure 19. Supply air temperature exit from the evaporator in a disturbance rejection test.

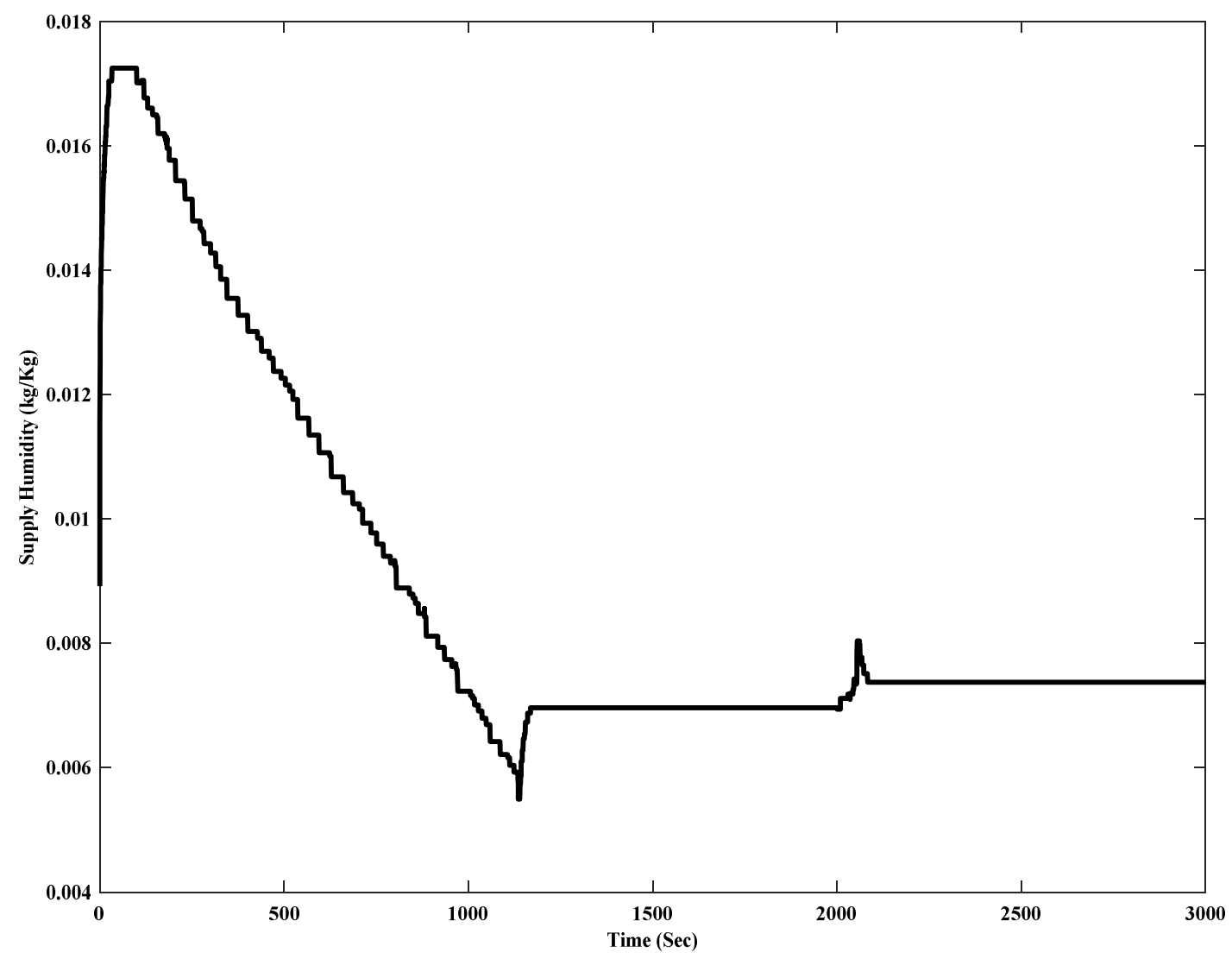

Figure 20. Supply humidity exit from the evaporator in a disturbance rejection test. 


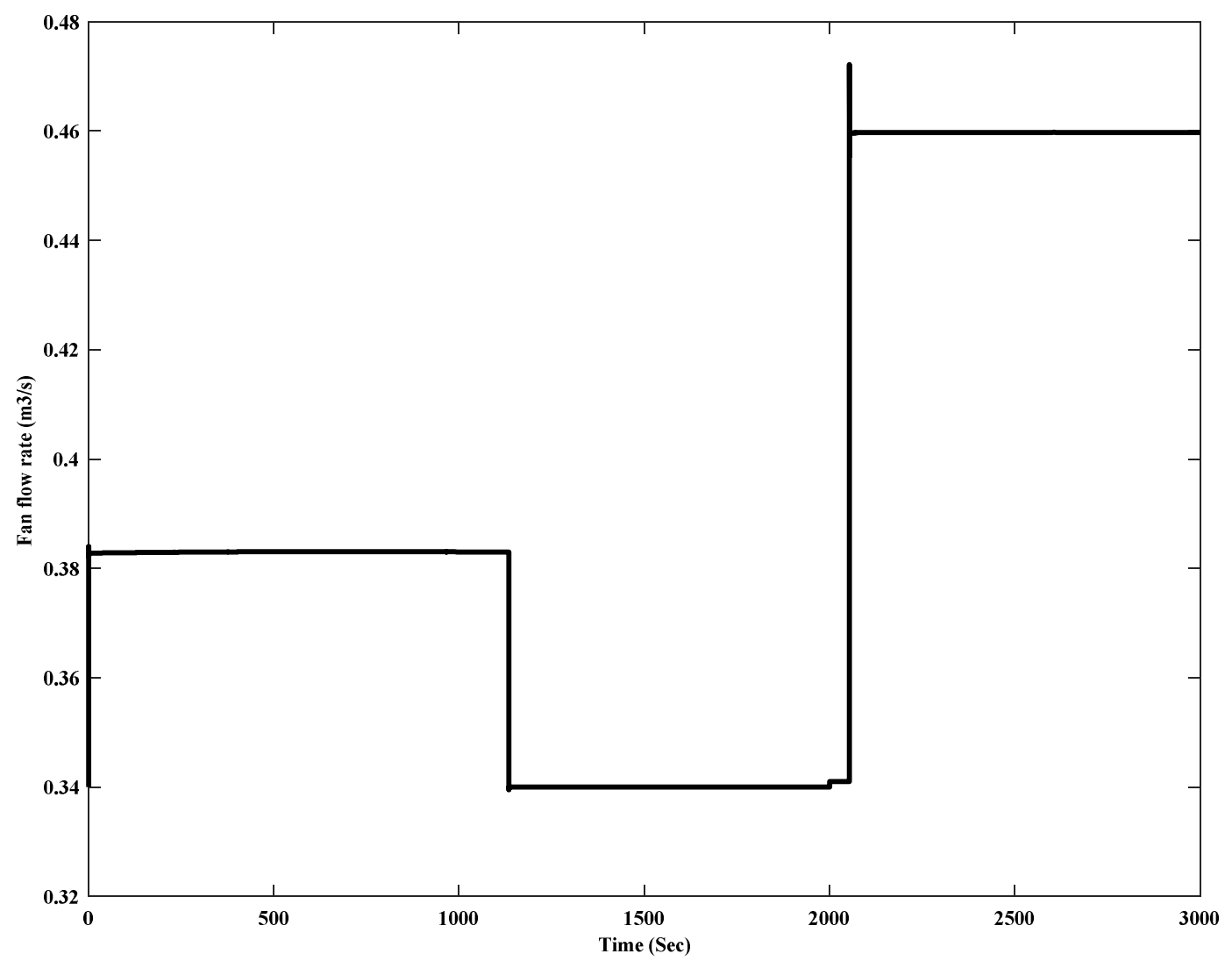

Figure 21. Flow rate of the fan in a disturbance rejection test.

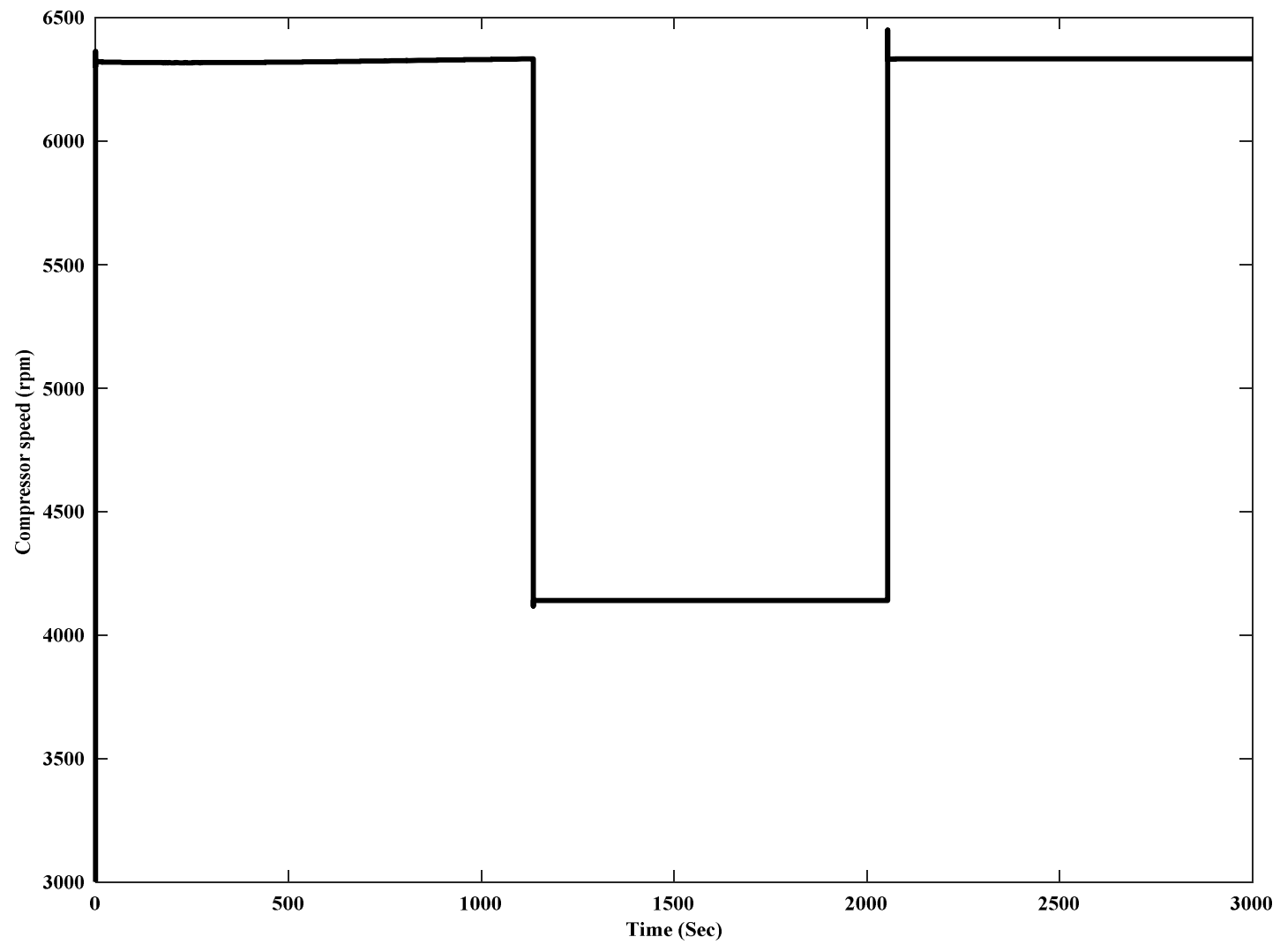

Figure 22. Speed of the motor compressor in a disturbance rejection test. 


\section{Discussion}

Because of the fact that the $\mathrm{A} / \mathrm{C}$ system is MIMO, and in most previous works it is considered a SISO system, artificially decoupling two strongly coupled feedback loops results in poor transient control performance [22]. The FCM construction has the ability to consider the coupled variables, and accordingly, the accuracy and sensitivity of control can be increased. In addition, the MIMO controllers have frequently been applied on the linearized model of the system in neighbourhoods of the operating point for simplicity. In other words, the system can merely work and be stable nearby a specific operating point. Thus, the controller cannot be implemented in a wide operating range. In contrast, the MIMO FCM based controller works on a wide operating range. Subject to HVAC and A/C systems, applying the nonlinear control methods was restricted, because of the difficult procedure to find the Lyapunov function, using of the entire states of the system, which causes the nonlinear observer requirement and difficult mathematical analysis. Because of having the complex and uncertain system, the need for a simple control algorithm and simple mathematics is feasible. As regards to the FCM structure and its ability for designing the controller on the basis of the system requirements and what outcomes are expected from the system, not in what way it works, the FCM method could be an appropriate solution for HVAC and A/C systems. The FCM method is able to consider the mentioned requirements of the system such as coupled parameters, MIMO, and nonlinear structures, in a single control structure. Not only the simple graph structure of the FCM method for designing the controller, but also the simple mathematics of the FCM method, are beneficial for obtaining the required control signals values with the intention of reaching the desired set points. In other words, the improvements by applying the FCM controller are avoiding complex and difficult mathematical analysis to design the controller; working in a wide operating range; making the nonlinear control design simple by observer elimination; decoupling cancellation and improving the sensitivity and accuracy of the system; reducing energy usage and improving energy efficiency; cancelling the overshoots and the undershoots due to the flexible and adaptable structure of the FCM; improving the transient behaviour of the system due to flexibility, adaptability, and convergence tendency of FCM; and using single control algorithm to integrate the DX A/C system's characteristics.

This section compares the results achieved by the designed FCM controller with the LQG controller by the authors of [22]. In order to compare the FCM controller with the LQG controller, the results of the both controller on the linear model of the system around $24{ }^{\circ} \mathrm{C}$ are compared in this section. Both controllers were tested on the linear model of the DX A/C system in initial room temperature of $24{ }^{\circ} \mathrm{C}$ and $50 \%$ room humidity or $0.0095 \mathrm{~kg} / \mathrm{Kg}$ humidity. The results of the LQG controller were adopted from the work of [22]. Figure 23 shows the results of the air-conditioned room temperature by applying LQG controller on linear model of the system around the operating point, Figure 24 shows the air-conditioned room humidity, Figure 25 shows the compressor speed, and Figure 26 shows the supply fan speed.

The air-conditioned room temperature is indicated in Figure 23. It is clearly seen that the temperature of the air-conditioned room stabilized around $24^{\circ} \mathrm{C}$. When the set point changed at $500 \mathrm{~s}$ to $23.5^{\circ} \mathrm{C}$, the air-conditioned room temperature declined from $24{ }^{\circ} \mathrm{C}$ to $23.5^{\circ} \mathrm{C}$. Increasing the supply fan flow rate and compressor speed, the temperature of the air-conditioned room decreased from $24^{\circ} \mathrm{C}$ in $520 \mathrm{~s}$ to $23.5^{\circ} \mathrm{C}$ at around $2000 \mathrm{~s}$. The temperature reaches the preferred set point in $25 \mathrm{~min}$ with no error and is maintained at the desired set point.

The air-conditioned room humidity is illustrated in Figure 24. As it is clear from the figure that the air-conditioned room humidity stabilized around $0.00965 \mathrm{~kg} / \mathrm{Kg}$. By changing the set point in $500 \mathrm{~s}$ to $23.5^{\circ} \mathrm{C}$, the humidity of the air conditioned room declined from $0.0095 \mathrm{~kg} / \mathrm{Kg}$ to $0.0093 \mathrm{~kg} / \mathrm{Kg}$. The humidity of the air-conditioned room decreased from $0.0095 \mathrm{~kg} / \mathrm{Kg}$ to $0.0093 \mathrm{~kg} / \mathrm{Kg}$ in about $2750 \mathrm{~s}$ with $2.5 \%$ error from $50 \%$ humidity by varying of the compressor speed and supply fan flow rate. Then, the air-conditioned room humidity stabilized at $0.0093 \mathrm{~kg} / \mathrm{Kg}$. 


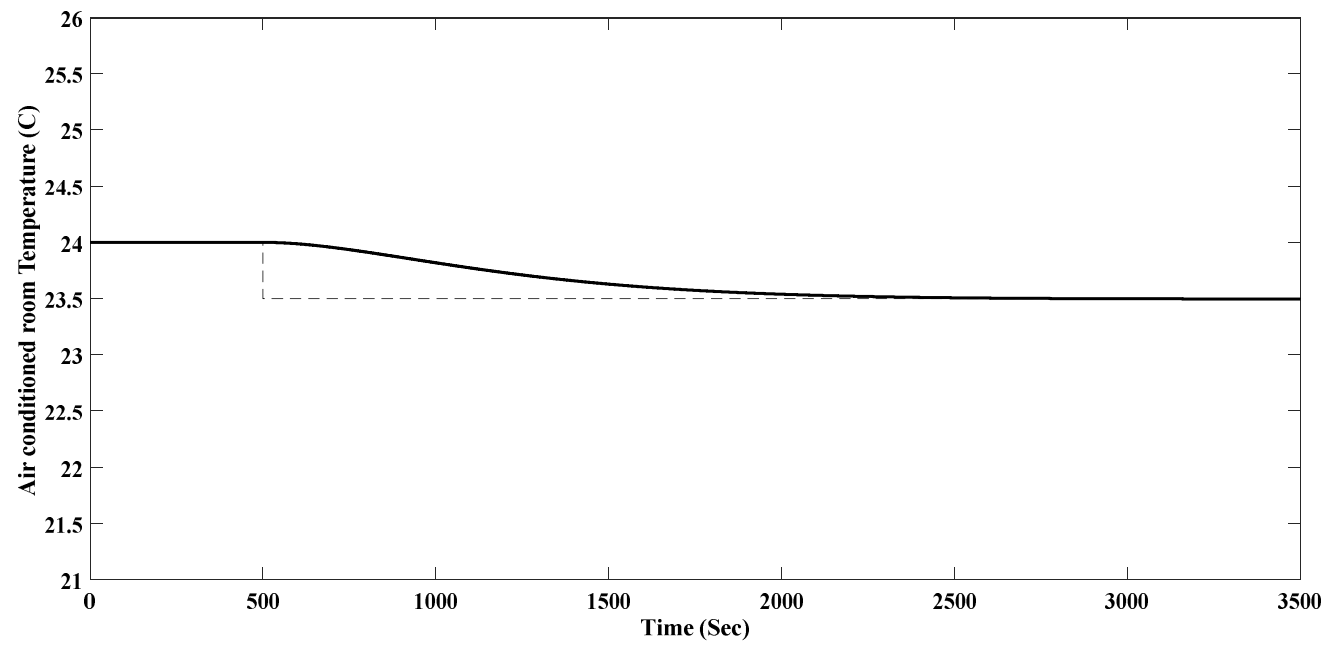

Figure 23. Simulation results of air-conditioned room temperature by applying the Linear Quadratic Gaussian (LQG) controller on the linear model of the system around the operating point.

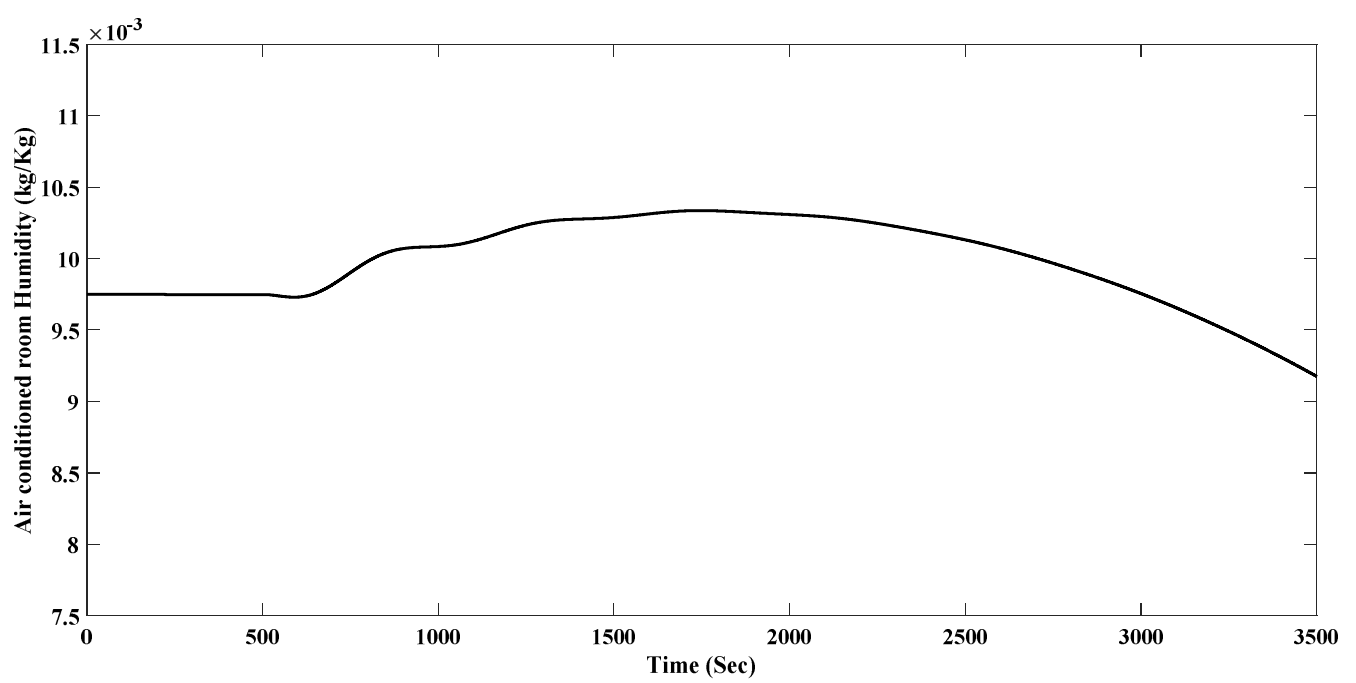

Figure 24. Simulation results of air-conditioned room humidity by applying the LQG controller on the linear model of the system around the operating point.

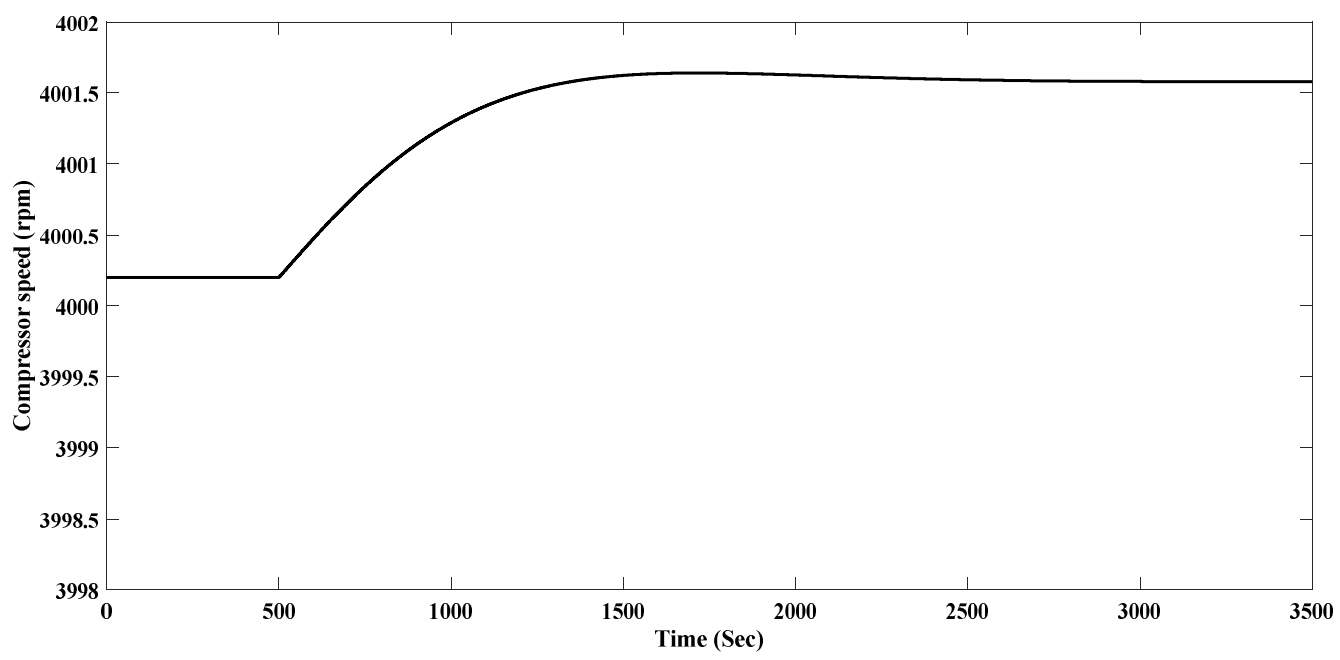

Figure 25. Simulation results of compressor speed by applying the LQG controller on the linear model of the system around the operating point. 
The speed of the compressor is depicted in Figure 25. Decline in the air-conditioned room temperature was obtained by increasing the compressor speed from $4000 \mathrm{rpm}$ to $4001.6 \mathrm{rpm}$ from $500 \mathrm{~s}$ to $1500 \mathrm{~s}$. In order to keep temperature and humidity of the room in preferred set points, the compressor speed maintained at $4001.6 \mathrm{rpm}$.

Figure 26 displays the supply fan speed. The fan speed raised from $2180 \mathrm{rpm}$ at $500 \mathrm{~s}$ to $2193 \mathrm{rpm}$ at $1500 \mathrm{~s}$ and maintained. While the air-conditioned room temperature achieved the preferred values, the fan speed maintained to the essential speed for keeping the air conditioned room humidity and temperature in chosen set points.

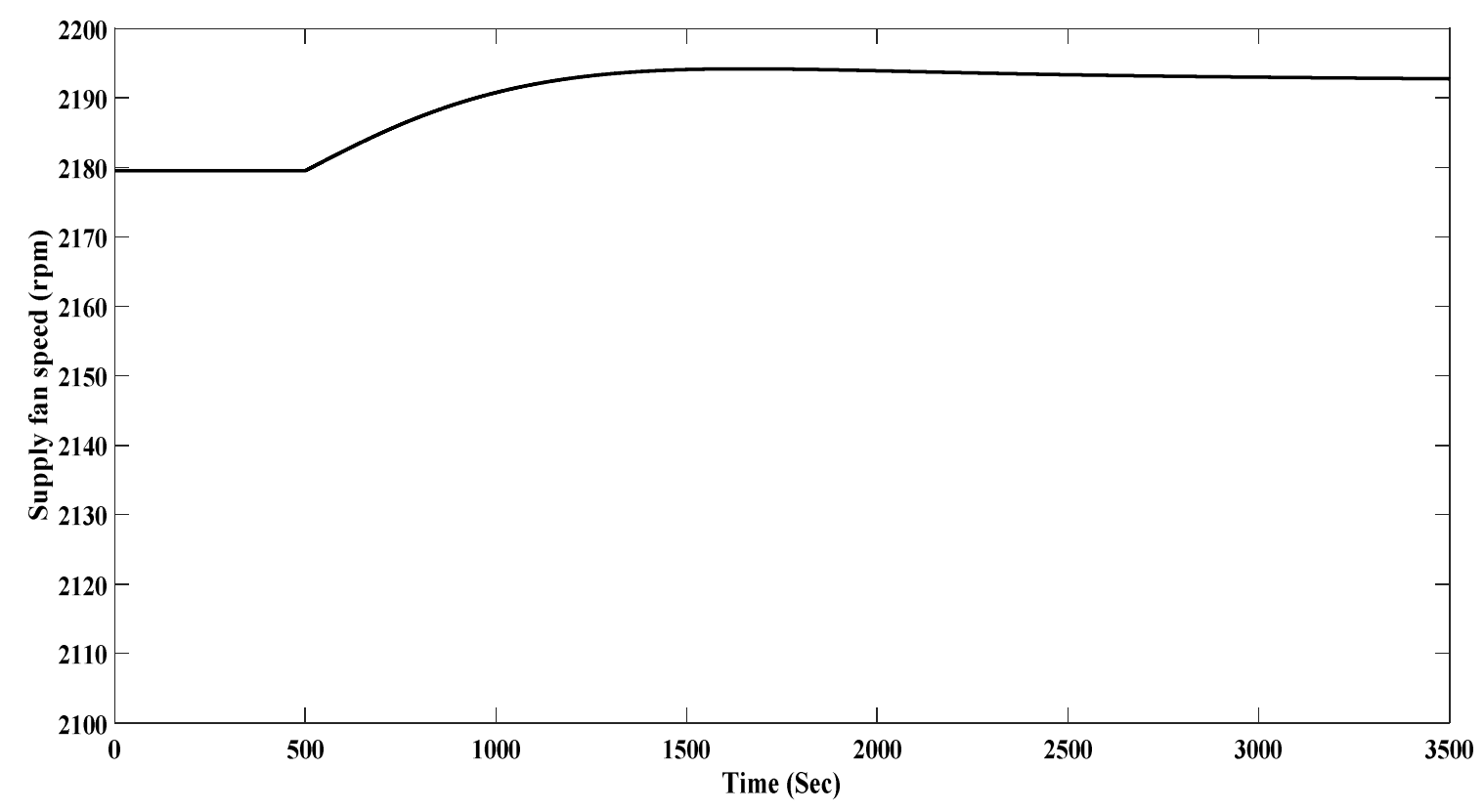

Figure 26. Simulation results of supply fan by applying the LQG controller on the linear model of the system around the operating point.

The results of the FCM controller on the linear model of the system around the operating point are shown as follows. The temperature of the air-conditioned room is indicated in Figure 27. It is clearly seen that the air-conditioned room temperature stabilized around $24{ }^{\circ} \mathrm{C}$. At $500 \mathrm{~s}$, the set point changed from $24^{\circ} \mathrm{C}$ to $23.5^{\circ} \mathrm{C}$. Therefore, by changing the set point, the air-conditioned room temperature reduced by varying the supply fan flow rate and compressor speed. The air-conditioned room temperature reduced from $24^{\circ} \mathrm{C}$ to $23.5^{\circ} \mathrm{C}$ at around $898 \mathrm{~s}$. The temperature stabilized in the preferred set point in $6.63 \mathrm{~min}$ with no error.

The humidity of the air-conditioned room is illustrated in Figure 28. As is clear from the figure, the air-conditioned room humidity stabilized around $0.0095 \mathrm{~kg} / \mathrm{Kg}$. By changing the set point in $500 \mathrm{~s}$ to $23.5^{\circ} \mathrm{C}$, the humidity of the air conditioned room declined from $0.0095 \mathrm{~kg} / \mathrm{Kg}$ to $0.0093 \mathrm{~kg} / \mathrm{Kg}$. By altering the supply fan flow rate and compressor speed, the air-conditioned room humidity reduced from $0.0095 \mathrm{~kg} / \mathrm{Kg}$ to $0.0093 \mathrm{~kg} / \mathrm{Kg}$ in about $1044 \mathrm{~s}$ with $1.25 \%$ error from $50 \%$ humidity. Then, the air-conditioned room humidity stabilized at $0.009257 \mathrm{~kg} / \mathrm{Kg}$ in about $1600 \mathrm{~s}$.

Figure 29 shows the speed of the compressor. For declining the temperature of the air-conditioned room, the compressor speed increased from $4000 \mathrm{rpm}$ to $4003 \mathrm{rpm}$ from $500 \mathrm{~s}$ to $689 \mathrm{~s}$. By declining the air-conditioned room temperature to the desired value, the speed of the compressor decreased and maintained at $4001 \mathrm{rpm}$ at $803 \mathrm{~s}$ to keep the air- conditioned room temperature and humidity in desired set points. 


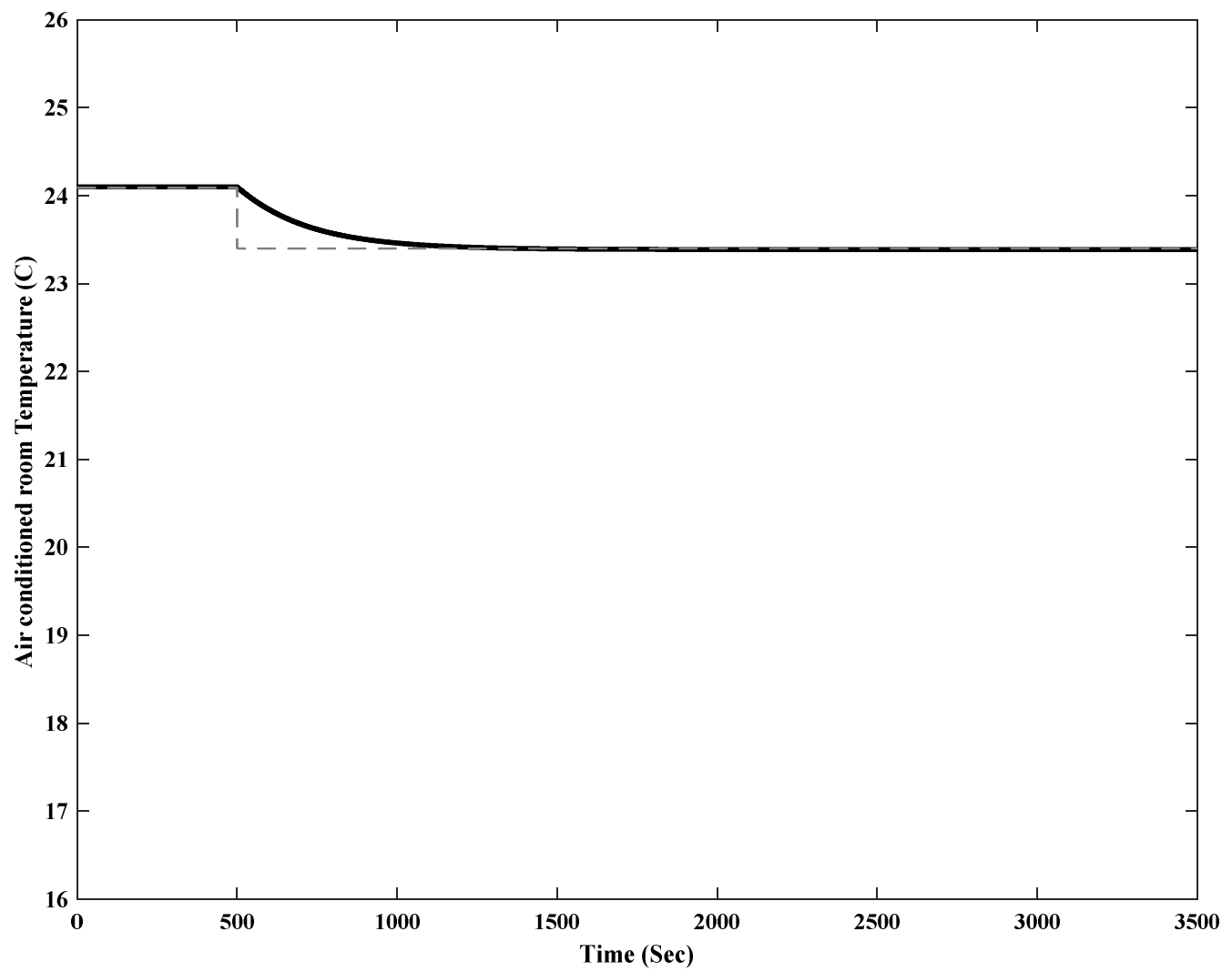

Figure 27. Simulation results of air-conditioned room temperature by applying the FCM controller on the linear model of the system around the operating point.

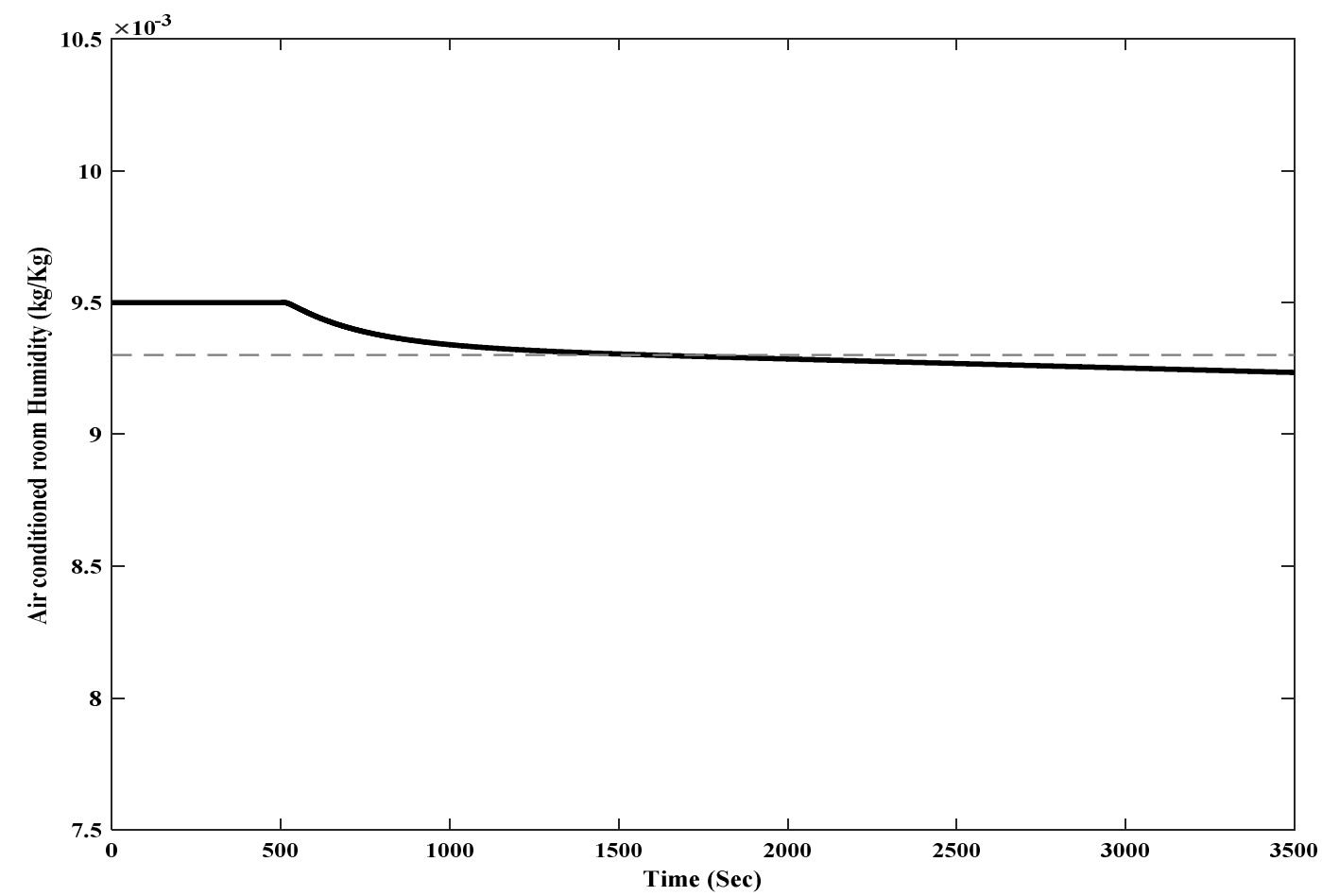

Figure 28. Simulation results of air-conditioned room humidity by applying the FCM controller on the linear model of the system around the operating point. 
The supply fan speed is shown in Figure 30. The fan speed increased from $2180 \mathrm{rpm}$ at $500 \mathrm{~s}$ to 2317 $\mathrm{rpm}$ at $1056 \mathrm{~s}$ and, after reaching the preferred values, it reduced to $2268 \mathrm{rpm}$ at $1779 \mathrm{~s}$ and maintained. After reaching the chosen set point for temperature of the room, at $1056 \mathrm{~s}$, the fan speed started to decline until it met the essential speed to keep the temperature and humidity of the air-conditioned room in chosen set points. The fan speed reduced to $2268 \mathrm{rpm}$ at $1779 \mathrm{~s}$ and maintained this speed.

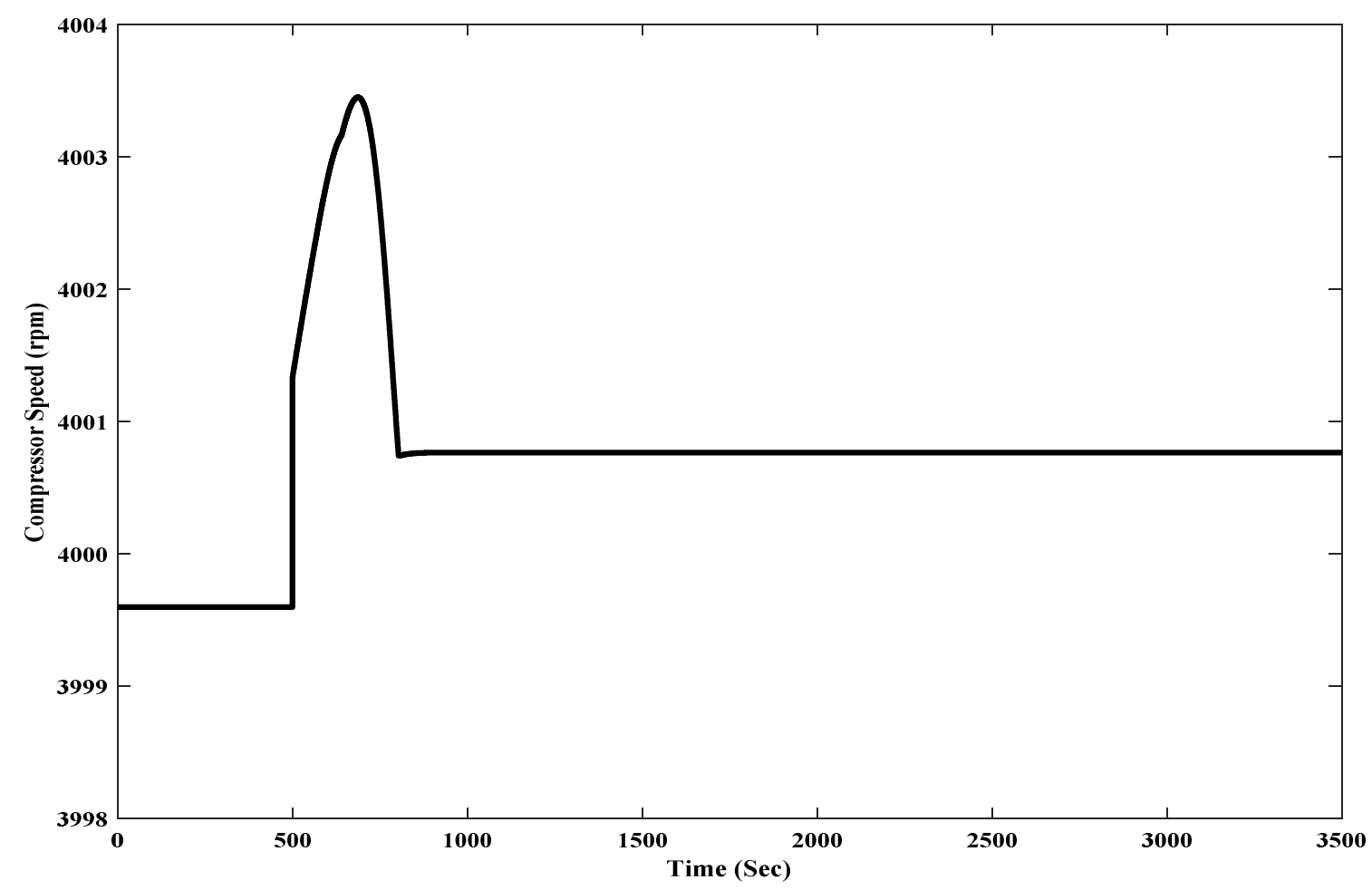

Figure 29. Simulation results of compressor speed by applying the FCM controller on the linear model of the system around the operating point.

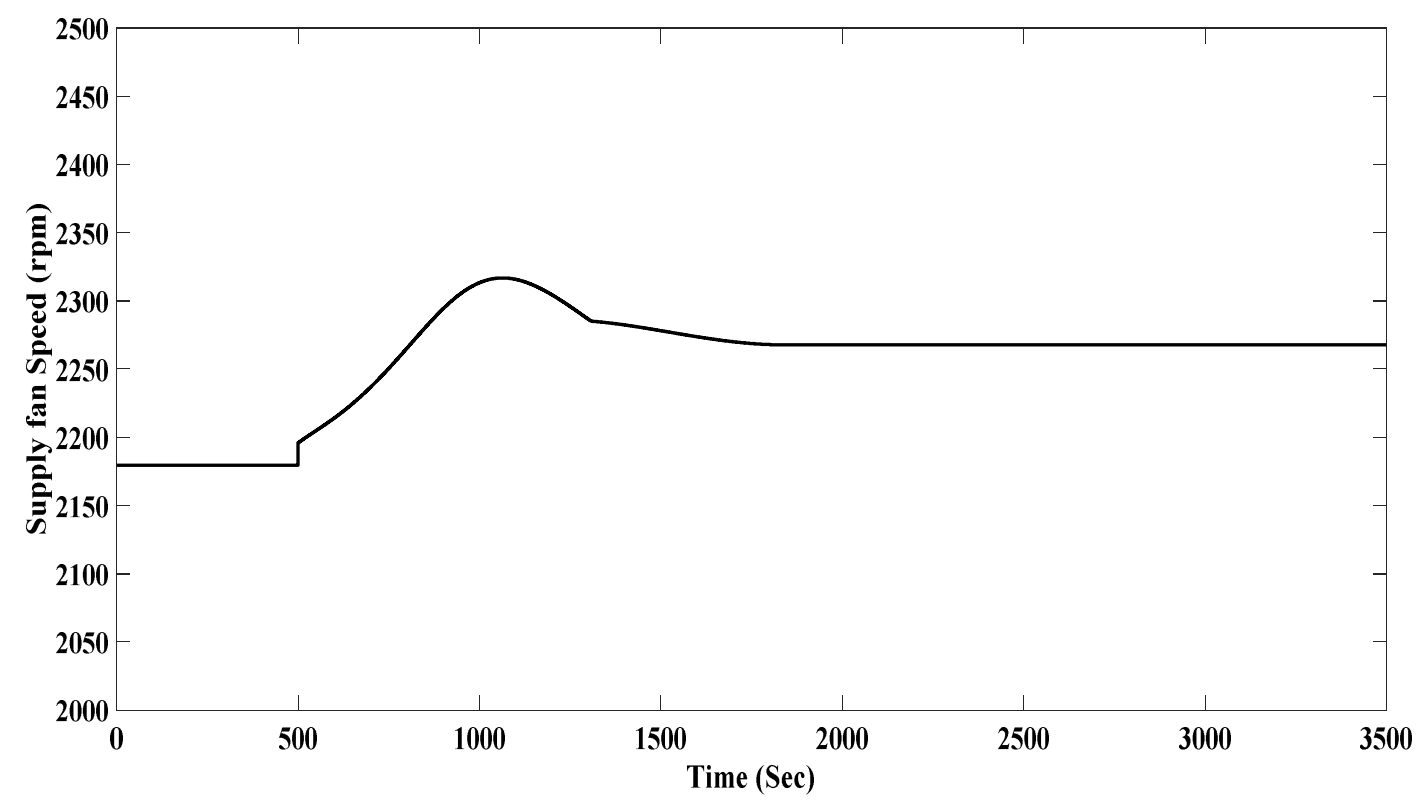

Figure 30. Simulation results of supply fan speed by applying the FCM controller on the linear model of the system around the operating point. 
The comparison between both controllers shows that the FCM controller managed to reach the desired set point for temperature of the air-conditioned room in $6.63 \mathrm{~min}$ with no error, while the LQG one managed to do so in $25 \mathrm{~min}$ with no error. In addition, the humidity of the air-conditioned room by the FCM controller reaches the desired set point after $544 \mathrm{~s}$ with $1.25 \%$ error, but the LQG one reaches the desired set point after $2250 \mathrm{~s}$ with $2.5 \%$ error. The benefits and shortcomings of both control methods are discussed as follows. Although the LQG controller has attractive features of thermal comfort and energy savings, rapid response [15], increased energy savings [15], and multivariable control [15], the disadvantages of the LQG control method are as follows.

- It was applied on the linear model of the system. Thus, it is not applicable for a wider operating range.

- The method is inherently complex. As a result, the optimal feedback control's evaluation and online implementation turn into a daunting challenge.

- The need to the model of the system. Thus, the appropriate model of the system should be identified [15].

On the other hand, the FCM controller avoids complex and difficult mathematical analysis to design the nonlinear controller. It works in a wide operating range and simplifies the designing of the nonlinear controller by removal of the observer. It improves the sensitivity and accuracy of the system by keeping the coupled structure of the system. The FCM controller is designed in a single control scenario for consideration of the system's characteristics. However, this control method is quite sensitive to the initial state values and to the type of concepts used in the FCM model, and it can give different results as they are different from and non-compatible with classic fuzzy.

The comparison of the two techniques' performances could be assessed by evaluating criteria such as integral square error (ISE), integral of absolute value of error (IAE), and integral of time-multiplied absolute value of error (ITAE). For these tests, the two controllers were tested under the same condition. The LQG controller was tested in initial room temperature of $30{ }^{\circ} \mathrm{C}$ and $80 \%$ room humidity or $0.02157 \mathrm{~kg} / \mathrm{Kg}$ humidity, and a desired temperature of $25^{\circ} \mathrm{C}$ and $50 \%$ humidity for comparison with the proposed FCM controller. Figure 31 shows the temperature of the air-conditioned room, which declined from $30^{\circ} \mathrm{C}$ to $22.88^{\circ} \mathrm{C}$ in $380 \mathrm{~s}$, and then after oscillation around $25^{\circ} \mathrm{C}$, it stabilized at $1200 \mathrm{~s}$ with small error. Figure 32 illustrates the humidity of the air-conditioned room, which reduced from $0.022 \mathrm{~kg} / \mathrm{Kg}$ to $0.008 \mathrm{~kg} / \mathrm{Kg}$, and it was unable to stabilize at certain values, which makes the system unstable. It is obviously seen that the LQG controller does not have the ability to control the humidity. The LQG controller is only able to control the condition around the operating point.

Table 2 shows the performance indexes results for both controllers based on the room temperature error. Table 3 indicates the performance indexes results for both controllers based on the room humidity error.

It is obvious from the results that the FCM controller has the ability to reduce the performance index. This means that for the real conditions of the room, the FCM controller works better than the LQG one. In other words, the FCM controller is more suitable and applicable. Also, the LQG controller was not able to control different conditions from the operating point and shows instability in the system. In other words, the LQG controller is severely dependant on the operating point, and changing the operating point makes the system unstable. In conditions where the controller is more dependent on the operating point, there is a need to design separate controllers for each operating point in the system. On the other hand, the Kalman filter in the LQG structure is suitable for linear systems or the linearized model of the nonlinear systems. As a result, working in wider operating points requires designing controllers for every operating point or using the multimodal controllers, or applying the extended Kalman filter (EKF) for calculating the operating point of the system in every second and extracting the required system parameters. By using each option in order to work in wider operating points, the volume of calculation is increased or designing the controller becomes complicated. The proposed FCM controller is not dependent on the operating point, and hence there is not a need to design more controllers at different operating points. 


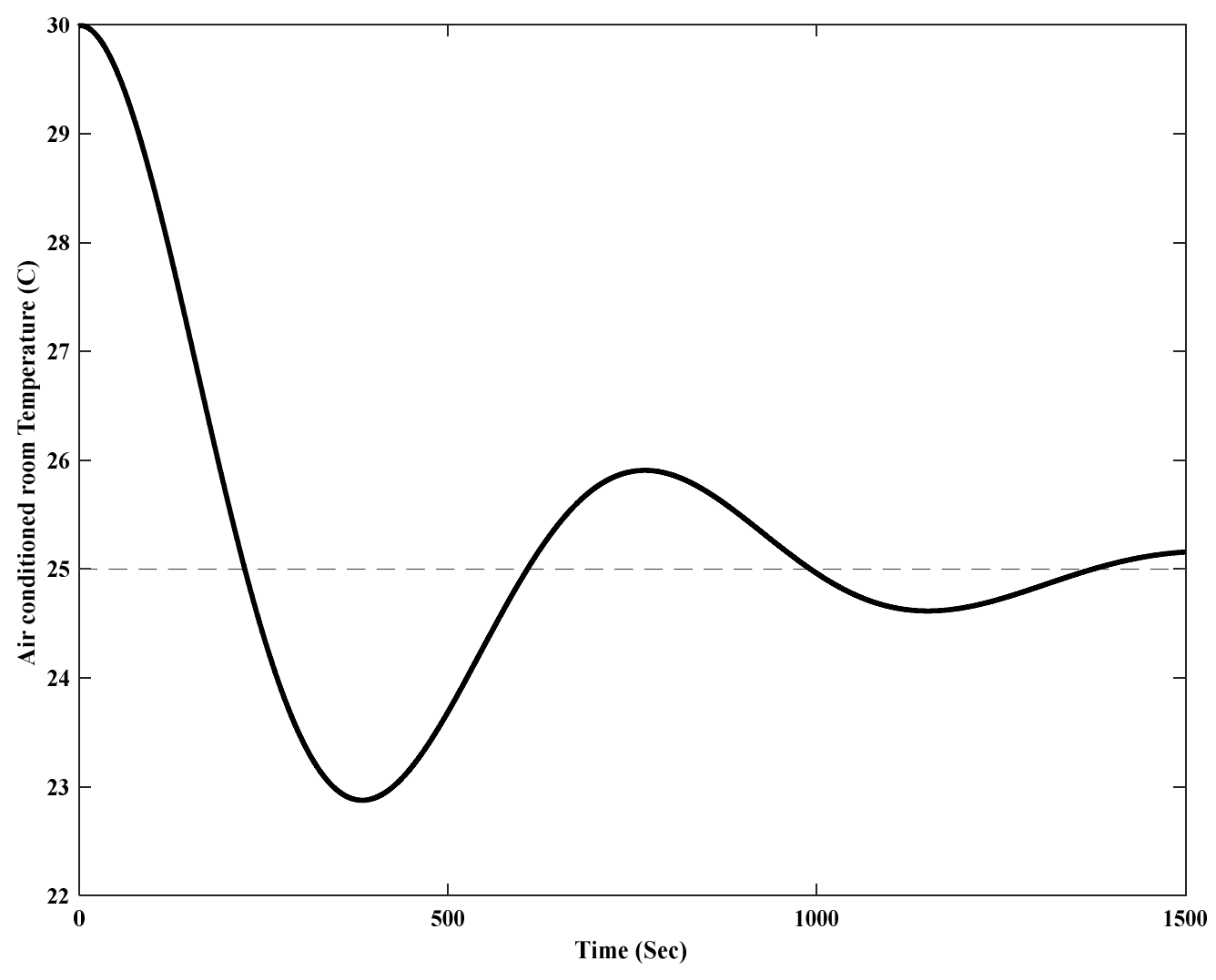

Figure 31. Temperature of the air-conditioned room by the LQG controller.

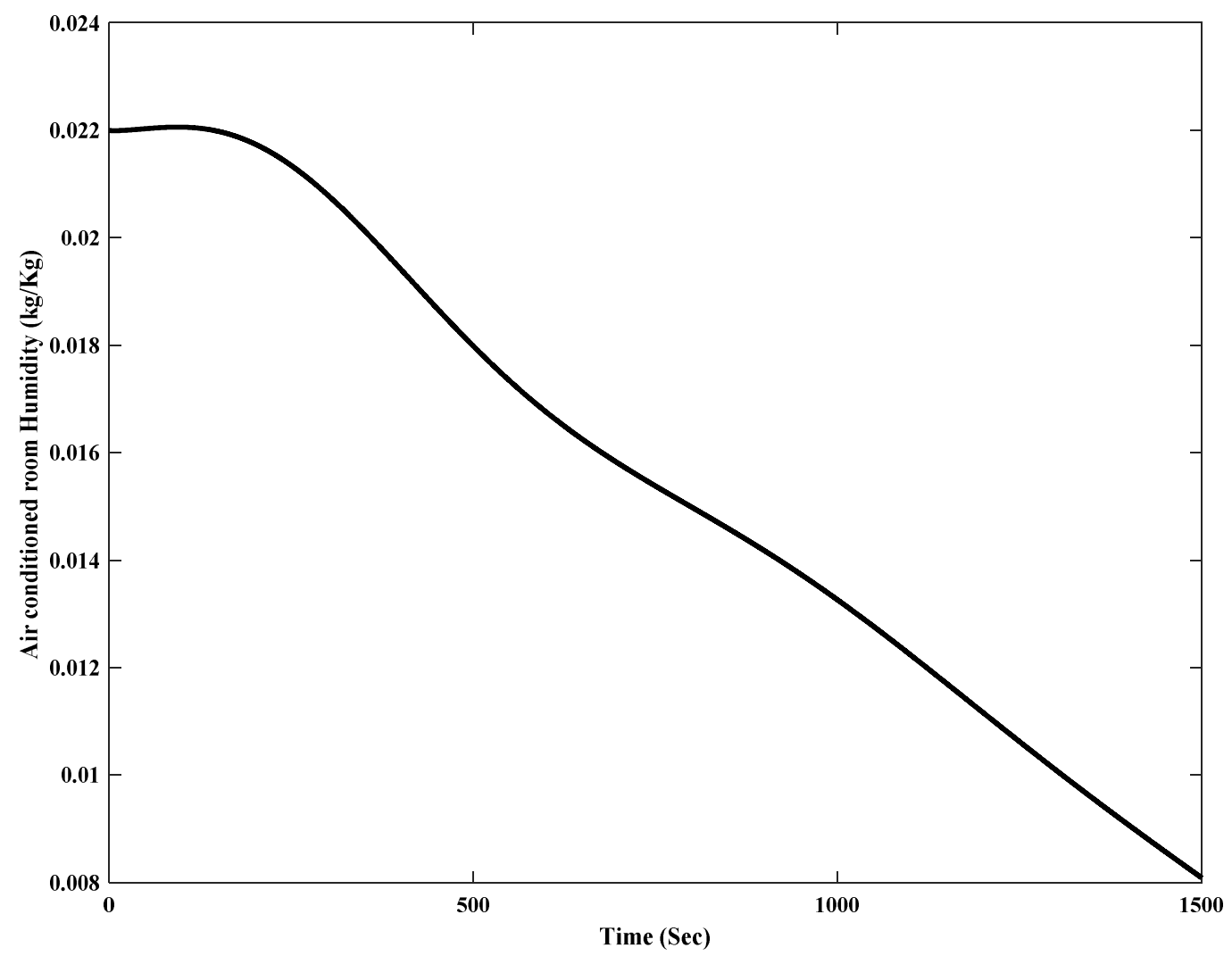

Figure 32. Humidity of the air-conditioned room by the LQG controller. 
Table 2. Results of the performance indexes for both controllers based on the room temperature error.

\begin{tabular}{cccc}
\hline \multirow{2}{*}{ Controller } & \multicolumn{3}{c}{ Performance index } \\
\cline { 2 - 4 } & ISE & IAE & ITAE \\
\hline LQG & $2.308 \times 10^{4}$ & 4096 & $1.763 \times 10^{6}$ \\
\hline FCM & 2857 & 1576 & $8.217 \times 10^{5}$ \\
\hline
\end{tabular}

Table 3. Results of the performance indexes for both controllers based on the room humidity error.

\begin{tabular}{cccc}
\hline \multirow{2}{*}{ Controller } & \multicolumn{3}{c}{ Performance index } \\
\cline { 2 - 4 } & ISE & IAE & ITAE \\
\hline LQG & 0.0602 & 7.719 & 3457 \\
\hline FCM & 0.05038 & 6.699 & 2674 \\
\hline
\end{tabular}

\section{Conclusion}

In this technical research, a new intelligent FCM control system was designed on the DX A/C system. This FCM control system could be easily designed for HVAC systems. The offered FCM controller is advantageous because of the graph structure of the FCM method, as well as its simple mathematics. Therefore, the FCM controller avoids the complex mathematical analysis, which is required to design the controller for a MIMO and nonlinear system with a complex structure. The proposed FCM controller met the requirements of designing a suitable controller for the DX A/C system. The requirements for designing the controller are consideration of nonlinearity, coupling effect, and MIMO structure, which are all considered in the offered FCM control method. The significance of this research is offering a new intelligent MIMO nonlinear controller for the DX A/C system. According to the results of the controller, the offered control system was designed easily and applied efficiently. The results obviously indicate the efficiency of the controller in the reference tracking signal. It is not successful only in the normal conditions but also in the occurrence of the heat and moisture loads disturbances works successfully. Designing the controller based on the FCM method does not require the mathematical model of the system and the suitable model of the system not like MPC method. It does not involve difficult mathematic analysis to derive the control law opposite to designing the nonlinear control or adaptive control methods. It has a wide operating range, unlike the MIMO controller, and it does not have overshoot and undershoot, which is different from the PID control method. Moreover, the stability of the FCM control method was proven by the Lyapunov function, as well as the FBAMs method. Therefore, the FCM control method can be designed for different nonlinear MIMO systems. Furthermore, it can be a suitable solution for designing the controller for the systems with no mathematical model or complex mathematical models.

Author Contributions: Conceptualization, Methodology, Software, Validation, Formal Analysis, Investigation, and Writing-Original Draft Preparation have done by F.B. Writing-Review \& Editing have done by R.Y., U.K. and Z.H.I. Supervision has done by N.M. Project Administration is R.Y. Funding Acquisition has done by U.K.

Funding: This research received no external funding.

Acknowledgments: The article has supported by the Universiti Teknologi Malaysia to publish in open access. I would like to thank Hossein Eliasi, Mohd Amran Mohd Radzi, Abdul Rahman Ramli and Mohammad Hamiruce Marhaban for their guidance in this research.

Conflicts of Interest: The authors declare no conflict of interest.

\section{References}

1. Tachwali, Y.; Refai, H.; Fagan, J. Minimizing HVAC Energy Consumption Using a Wireless Sensor Network. In Proceedings of the IECON 2007 33rd Annual Conference of the IEEE Industrial Electronics Society, Taipei, Taiwan, 5-8 November 2007; pp. 439-444. 
2. Tashtoush, B.; Molhim, M.; Al-Rousan, M. Dynamic model of an HVAC system for control analysis. Energy 2005, 30, 1729-1745. [CrossRef]

3. Qi, Q.; Deng, S.S. Multivariable control-oriented modeling of a direct expansion (DX) air conditioning (A/C) system. Int. J. Refrig. 2008, 31, 841-849. [CrossRef]

4. Qi, Q.; Deng, S.S. Multivariable control of indoor air temperature and humidity in a direct expansion (DX) air conditioning (A/C) system. Build. Environ. 2009, 44, 1659-1667. [CrossRef]

5. Wang, J.; An, D.; Lou, C. Application of Fuzzy-PID Controller in Heating Ventilating and Air-Conditioning System. In Proceedings of the 2006 International Conference on Mechatronics and Automation, Luoyang, China, 25-28 June 2006; pp. 2217-2222.

6. Lei, J.; Hongli, L.; Cai, W. Model Predictive Control Based on Fuzzy Linearization Technique FOR HVAC Systems Temperature Control. In Proceedings of the 2006 1ST IEEE Conference on Industrial Electronics and Applications, Singapore, 24-26 May 2006; pp. 1-5.

7. Matysko, R. Theoretical model of the operation parameters regulated by the MIMO and SISO system in a cooling chamber. Int. J. Refrig. 2015, 58, 53-57. [CrossRef]

8. Huang, G. Model predictive control of VAV zone thermal systems concerning bi-linearity and gain nonlinearity. Control Eng. Pract. 2011, 19, 700-710. [CrossRef]

9. Lü, H.; Jia, L.; Kong, S.; Zhang, Z. Predictive functional control based on fuzzy T-S model for HVAC systems temperature control. J. Control Theory Appl. 2007, 5, 94-98. [CrossRef]

10. Mirinejad, H.; Ghasemian, M.; Torab, H.; Sadati, S.H. Control Techniques in Heating, Ventilating and Air Conditioning (HVAC) Systems. J. Comput. Sci. 2008, 4, 777-783. [CrossRef]

11. Venkatesh, S.; Sundaram, S. Intelligent Humidity Control for Healthy Home to Wealthy Industry: A Review. Res. J. Inf. Technol. 2012, 4, 73-84. [CrossRef]

12. Kassai, M. Experimental investigation on the effectiveness of sorption energy recovery wheel in ventilation system. Exp. Heat Transf. 2017, 31, 106-120. [CrossRef]

13. Gruber, P.; Balemi, S. Overview of non-linear control methods; Technical Report; Swiss society for automatic control: St. Gallen, Switzerland, 2010.

14. Afram, A.; Janabi-Sharifi, F. Theory and applications of HVAC control systems-A review of model predictive control (MPC). Build. Environ. 2014, 72, 343-355. [CrossRef]

15. Perera, D.W.U.; Pfeiffer, C.F.; Skeie, N.O. Control of temperature and energy consumption in building-A review. Int. J. Energ. Environ. 2014, 5, 471-484.

16. Kozák, Š. State-of-the-art in control engineering. J. Electr. Syst. Inf. Technol. 2014, 1, 1-9. [CrossRef]

17. Kassai, M.; Kajtar, L.; Nyers, J. Experimental optimization of energy consumption for DC refrigerator by PID controller tuning and comparison with On-Off refrigerator. Therm. Sci. 2019, 23, 941-952. [CrossRef]

18. Raut, K.H.; Vaishnav, S.R. A study on Performance of Different PID Tuning Techniques. In Proceedings of the International Conference on Electrical Engineering and Computer Science, Trivandrum, India, 12 May 2012; pp. 250-254.

19. Yan, Y.; Song, Y.; Wu, S. Control strategies for indoor environment quality and energy efficiency-A review. Int. J. Low-Carbon Technol. 2013, 10, 305-312.

20. Shiming, D. A dynamic mathematical model of a direct expansion (DX) water-cooled air-conditioning plant. Build. Environ. 2000, 35, 603-613. [CrossRef]

21. Shiming, D. The application of feedforward control in a direct expansion (DX) air conditioning plant. Build. Environ. 2002, 37, 35-40.

22. Qi, Q. Multivariable Control of Air Temperature and Humidity in a Space Served by Direct Expansion Air Conditioning System. Ph.D. Thesis, Polytechnic University, Hong Kong, China, 2009.

23. Papageorgiou, E.; Stylios, C.; Groumpos, P.; Papageorgiou, E. Active Hebbian learning algorithm to train fuzzy cognitive maps. Int. J. Approx. Reason. 2004, 37, 219-249. [CrossRef]

24. Huerga, A. A Balanced Differential Learning Algorithm in Fuzzy Cognitive Maps. In Proceedings of the 16th International Workshop on Qualitative Reasoning, Barcelona, Spain, 2 June 2002; pp. 10-12.

25. Khor, S.; Khan, M. Scenario Planning Using Fuzzy Cognitive Maps. In Proceedings of the ANZIIS2003 8th Australian and New Zealand Intelligent Information Systems Conference, Sydney, Australia, 10-12 December 2003; pp. 311-316.

26. Kosko, B. Fuzzy cognitive maps. Int. J. Man. Mach. Stud. 1986, 24, 65-75. [CrossRef] 
27. Axelord, R. Structure of Decision: The Cognitive Maps Political Elites; Princeton University Press: Princeton, NJ, USA, 1976.

28. Stylios, C.; Groumpos, P. Fuzzy cognitive maps in modeling supervisory control systems. J. Intell. Fuzzy Syst. 2000, 8, 83-98.

29. Kim, M.C.; Kim, C.O.; Hong, S.R.; Kwon, I.H. Forward-backward analysis of RFID-enabled supply chain using fuzzy cognitive map and genetic algorithm. Expert Syst. Appl. 2008, 35, 1166-1176. [CrossRef]

30. Bertolini, M. Assessment of human reliability factors: A fuzzy cognitive maps approach. Int. J. Ind. Ergon. 2007, 37, 405-413. [CrossRef]

31. Aguilar, J. A survey about fuzzy cognitive maps papers (Invited paper). Int. J. Comput. Cogn. 2005, 3, 27.

32. Behrooz, F.; Ramli, A.R.; Samsudin, K. A survey on applying different control methods approach in building automation systems to obtain more energy efficiency. Int. J. Phys. Sci. 2011, 6, 2308-2314.

33. Stylios, C.; Groumpos, P. Modeling Complex Systems Using Fuzzy Cognitive Maps. IEEE Trans. Syst. Man Cybern. Part A Syst. Hum. 2004, 34, 155-162. [CrossRef]

34. Behrooz, F.; Mariun, N.B.; Marhaban, M.H.; Radzi, M.A.; Ramli, A.R. New Design Approach to MIMO Nonlinear Controller for Direct Expansion Air Conditioning System in Building Automation System. In Proceedings of the 2015 IEEE 15th International Conference on Environment and Electrical Engineering (EEEIC), Rome, Italy, 10-13 June 2015; pp. 1706-1712.

35. Rossiter, A. Generalised Predictive Control, Videos on model predictive control. Creative Commons, USA: Attribution 2.0 UK: England \& Wales Licence, 2014; Vol. chapter 2. Available online: https: //www.sheffield.ac.uk/acse/people/jar/mpcmaster (accessed on 12 July 2019).

36. Behrooz, F.; Ramli, A.R.; Samsudin, K.; Eliasi, H. Energy saving by applying the fuzzy cognitive map control in controlling the temperature and humidity of room. Int. J. Phys. Sci. 2017, 12, 13-23.

37. Martchenko, A.S.; Ermolov, I.L.; Groumpos, P.P.; Poduraev, J.V.; Stylios, C.D. Investigating Stability Analysis Issues for Fuzzy Cognitive Maps. In Proceedings of the 11th Mediterranean Conference on Control and Automation MED'03, Rhodes, Greece, 18-20 June 2003.

38. Cheng, Q.; Fan, Z.T. The stability problem for fuzzy bidirectional associative memories. Fuzzy Sets. Syst. 2002, 132, 83-90. [CrossRef]

39. Ge, S. Lyapunov Design, in Knowledge Foundations; Eolss Publishers: Oxford, UK, 2004.

40. Cannon, M. Nonlinear systems. Lectures Hilary Term 2016. Available online: https://markcannon.github.io/ teaching/ (accessed on 12 July 2019).

41. Li, H.; Yang, B.; Xie, Y.; Qian, W.A. Multi-relationship Fuzzy Cognitive Map Stability Method. J. Inf. Comput. Sci. 2013, 10, 5373-5379. [CrossRef]

(C) 2019 by the authors. Licensee MDPI, Basel, Switzerland. This article is an open access article distributed under the terms and conditions of the Creative Commons Attribution (CC BY) license (http://creativecommons.org/licenses/by/4.0/). 